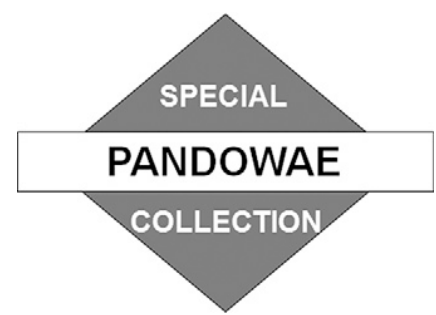

\title{
The Key Role of Diabatic Outflow in Amplifying the Midlatitude Flow: A Representative Case Study of Weather Systems Surrounding Western North Pacific Extratropical Transition $\mathscr{O}$
}

\author{
CHRISTIAN M. GRAMS \\ Institute for Atmospheric and Climate Science, ETH Zurich, Zurich, Switzerland \\ HeAther M. ARChAmBAult ${ }^{\mathrm{a}}$ \\ Department of Meteorology, Naval Postgraduate School, Monterey, California
}

(Manuscript received 5 December 2015, in final form 1 July 2016)

\begin{abstract}
Recurving tropical cyclones (TCs) undergoing extratropical transition (ET) may substantially modify the large-scale midlatitude flow pattern. This study highlights the role of diabatic outflow in midlatitude flow amplification within the context of a review of the physical and dynamical processes involved in ET. Composite fields of 12 western North Pacific ET cases are used as initial and boundary conditions for high-resolution numerical simulations of the North Pacific-North American sector with and without the TC present. It is demonstrated that a three-stage sequence of diabatic outflow associated with different weather systems is involved in triggering a highly amplified midlatitude flow pattern: 1) preconditioning by a predecessor rain event (PRE), 2) TC-extratropical flow interaction, and 3) downstream flow amplification by a downstream warm conveyor belt (WCB). An ensemble of perturbed simulations demonstrates the robustness of these stages. Beyond earlier studies investigating PREs, recurving TCs, and WCBs individually, here the fact that each impacts the midlatitude flow through a similar sequence of processes surrounding ET is highlighted. Latent heat release in rapidly ascending air leads to a net transport of low-PV air into the upper troposphere. Negative PV advection by the diabatically driven outflow initiates ridge building, accelerates and anchors a midlatitude jet streak, and overall amplifies the upper-level Rossby wave pattern. However, the three weather systems markedly differ in terms of the character of diabatic heating and associated outflow height, with the TC outflow reaching highest and the downstream WCB outflow producing the strongest negative PV anomaly.
\end{abstract}

\section{Introduction}

The large-scale midlatitude flow is dominated by the upper-level jet stream that serves as a waveguide for Rossby waves (e.g., Martius et al. 2010). Because their

Supplemental information related to this paper is available at the Journals Online website: http://dx.doi.org/10.1175/ MWR-D-15-0419.s1.

${ }^{a}$ Current affiliation: NOAA/Climate Program Office, Silver Spring, Maryland.

Corresponding author address: Christian M. Grams, Institute for Atmospheric and Climate Science, ETH Zurich, Universitaetstr. 16, CH-8092 Zurich, Switzerland.

E-mail: christian.grams@env.ethz.ch general evolution follows dry dynamics that can be represented at grid scale in numerical weather prediction (NWP) models, Rossby waves may be expected to feature a high degree of predictability (Grazzini and Vitart 2015). However, major forecast uncertainty and error in the midlatitudes in current NWP models have recently been shown to be linked to a misrepresentation of the Rossby wave pattern and various authors pointed to the potential role of moist processes in large-scale flow modification (e.g., Grams et al. 2011; Davies and Didone 2013; Rodwell et al. 2013; Gray et al. 2014; Teubler and Riemer 2016). Enhanced forecast uncertainty for the large-scale flow evolution has also been documented downstream of extratropical transition (ET; Jones et al. 2003; Anwender et al. 2008; Aiyyer 2015; Grams et al. 
2015; Quinting and Jones 2016). Research during the last few decades has related the modulation of the midlatitude Rossby wave pattern during ET to the strong latent heat release by the transitioning TC. In essence, the upper-level divergent outflow of the transitioning TC impinging on the midlatitude waveguide enhances ridge building (e.g., Bosart and Lackmann 1995; Riemer et al. 2008; Archambault et al. 2013), in addition to the balanced flow, and triggers downstream dispersion of Rossby waves (e.g., Riemer and Jones 2010; Grams et al. 2013a; Archambault et al. 2015; Torn and Hakim 2015; Quinting and Jones 2016). The divergent outflow and initial ridge building results from the diabatically driven strong ascent and associated latent heat release in the $\mathrm{TC}$ inner core and later at the midlatitude baroclinic zone yielding a net transport of lower-tropospheric air with low values of potential vorticity (PV) to the tropopause (e.g., DiMego and Bosart 1982; Bosart and Lackmann 1995; Torn 2010; Grams et al. 2013b). Also, other weather systems such as predecessor rain events (PREs; Galarneau et al. 2010; Moore et al. 2013) and warm conveyor belts (WCBs; e.g., Carlson 1980; Madonna et al. 2014b) occur surrounding an ET event, exhibit strong diabatic outflow, and may modify the upper-level Rossby wave pattern in a similar manner as the actual ET (Ahmadi-Givi et al. 2004; Grams et al. 2011; Bosart et al. 2012; Lang and Martin 2013; Moore et al. 2013; Madonna et al. 2014a; Galarneau 2015; Teubler and Riemer 2016). The diabatic nature of this interaction alters the behavior of Rossby waves expected from a purely dry dynamical perspective.

In this study we aim for a synthesis of the characteristics of weather systems surrounding an ET event and for documenting their role within the general context of midlatitude flow amplification. In contrast to previously studied aspects of ET, our focus expands from the transitioning TC to include a discussion of the role and character of diabatic outflow by other weather systems. A multiscale case study based on a combination of the observational composite approach of Archambault et al. (2015) with the modeling case study approach of Grams et al. (2013b) serves as a representative scenario for strong midlatitude flow amplification surrounding ET. This approach allows for a comprehensive, holistic view of the physical and dynamical processes governing midlatitude flow modification during and after ET. In addition, the characteristics of the different weather systems involved in ET are contrasted and their modification by ET is explored.

The study is organized as follows. A brief review of diabatic processes during TC-extratropical flow interaction is given in section 2 . The construction of a composite of 12 western North Pacific September ET cases used as initial data for numerical simulations with the mesoscale Consortium for Small-Scale Modeling (COSMO) model with and without the TC present and additional diagnostic tools used to analyze the data are explained in section 3. Section 4 gives an overview of the robust features of the ET scenario in the composite, within the individual cases constituting the composite, and in the numerical simulations. Known aspects of TC-midlatitude flow interaction are explained based on this ET scenario and are expanded upon the other key weather systems from an Eulerian perspective in section 5 . The characteristics of diabatic outflow associated with these weather systems are contrasted from a Lagrangian perspective in section 6. We summarize our results with a conceptual view of western North Pacific ET in section 7 and conclude the paper with a discussion (section 8). Although background (section 2) and a comprehensive discussion of the midlatitude impact of ET (section 5) are provided for the interested reader, note that it is possible to bypass these two sections without compromising the understanding of the main elements of the study.

\section{Background on TC-extratropical flow interaction}

The upper-level diabatic TC outflow is a key element of the interaction of the TC with the midlatitude flow during ET. The TC outflow is associated with a pronounced negative PV anomaly near the tropopause and is often concentrated in an equatorward outflow jet that becomes directed downshear and poleward from the TC as the TC approaches the midlatitudes (e.g., $\mathrm{Wu}$ and Kurihara 1996). The diabatic outflow of the transitioning TC is driven by the joint interactions of (i) the low- and midlevel TC circulation with a preexisting midlatitude baroclinic zone and of (ii) the upper-level TC circulation with the upper-level midlatitude waveguide. Early on during ET, strong latent heat release enhances convective ascent in the TC inner core. Air parcels with low PV enter the TC in the lower troposphere. Below the midtropospheric heating maximum, PV strongly increases. Above the heating maximum, PV is strongly diabatically reduced (cf. Wernli and Davies 1997, Fig. 4 therein). As a net effect, low-PV air is transported from low levels to the upper troposphere (e.g., Torn 2010; Grams et al. 2013b). In the upper levels the TC outflow advects this low-PV air almost isentropically poleward (e.g., Archambault et al. 2013). Thus, the injection of a low-PV air mass into the upperisentropic layer, which is subsequently transported 
adiabatically by the TC outflow, results in a lifting of the tropopause, an enhanced tropopause PV gradient, and an acceleration of the jet (cf. Thorncroft and Jones 2000). At the same time the tropopause waveguide is deflected poleward and a ridge builds directly downstream of the transitioning TC. Later during ET, when the low- and midlevel TC circulation impinges on the midlatitude baroclinic zone, strong slantwise ascent becomes established and maintains the latent heat release, upper-level ridge building, and the jet streak (e.g., DiMego and Bosart 1982; Bosart and Lackmann 1995; Atallah and Bosart 2003; Torn 2010; Grams et al. 2013b). Recently, Quinting and Jones (2016) demonstrated that the ascent during ET is strongly enhanced by moist processes and that dry dynamics only account for roughly a third of the ascent observed during ET. As argued by Harr and Elsberry (2000) and Agustí-Panareda et al. (2004), the transition from convective, vertical ascent to slantwise ascent along the (moist-) isentropes in the developing warm sector may be regarded as the gradual evolution of a WCB (cf. Grams et al. 2013b). A similar impact of strong latent heat release on the upper-level flow has been reported for midlatitude weather systems (e.g., Ahmadi-Givi et al. 2004; Grams et al. 2011; Lang and Martin 2013; Teubler and Riemer 2016).

The interaction of the diabatic outflow with the upperlevel midlatitude flow during ET is critical in favoring Rossby wave triggering or amplification. Recent studies documented a statistically significant increase in the frequency and amplitude of Rossby wave packets downstream of western North Pacific ET (e.g., Quinting and Jones 2016). Archambault et al. (2013) introduced an objective metric to quantify the strength of the TC-extratropical flow interaction in terms of the negative PV advection by the irrotational wind. They and other studies documented that during ET the advection of low-PV air by the TC divergent outflow anchors the midlatitude jet, resulting in initial ridge building, a reduction of the phase speed, and a retardation in the eastward propagation of Rossby waves (e.g., Riemer et al. 2008; Riemer and Jones 2010; Grams et al. 2013a; Archambault et al. 2015). Various idealized and real case studies demonstrated that the downstream Rossby wave dispersion due to ET is highly sensitive to the phasing of the recurving TC and midlatitude flow features (Ritchie and Elsberry 2007; Archambault et al. 2013, 2015) and showed the existence of a bifurcation point for the track of the TC in the trough-relative steering flow during ET (Scheck et al. 2011b; Grams et al. 2013a; Riemer and Jones 2014).
Because of the sensitivity of the midlatitude flow response to the complex interaction of the TC with midlatitude flow features, NWP models often show increased forecast uncertainty for the downstream midlatitude flow surrounding an ET event (Anwender et al. 2008; Harr et al. 2008; Keller et al. 2011; Aiyyer 2015; Grams et al. 2015; Quinting and Jones 2016). This uncertainty may be introduced by the parameterization of diabatic processes. An improved understanding of the physical and dynamical processes governing this interaction could ultimately help to improve NWP and to yield improved forecast guidance during ET episodes.

Another aspect of ET is its potential to cause highimpact weather (HIW) events such as heavy rain, strong winds, ocean swells, or wild fire conditions directly related to the transitioning TC (Sekioka 1959; Foley and Hanstrum 1994; Browning et al. 1998; Harr and Elsberry 2000; Klein et al. 2000; McTaggart-Cowan et al. 2001; Atallah and Bosart 2003; Jones et al. 2003). However, in remote regions away from the transitioning TC, the dispersion of downstream Rossby waves can trigger HIW as well (Cordeira and Bosart 2010; Grams 2011; Archambault et al. 2013; Keller and Grams 2014; Grams and Blumer 2015; Harr and Archambault 2016; Pantillon et al. 2015). Lately, attention has been paid to the enhanced poleward moisture transport that occurs often on the eastern side of a transitioning TC. When this moisture impinges on a midlatitude baroclinic zone in a region of upperlevel forcing for ascent [e.g., near the equatorward entrance region of an upper-level jet streak; Uccellini and Johnson (1979)] several days prior to ET, heavy precipitation and flooding may occur as a result of quasistationary convection in that region (e.g., Wang et al. 2009; Galarneau et al. 2010; Byun and Lee 2012; Schumacher and Galarneau 2012; Baek et al. 2013). The associated weather system, called a predecessor rain event (PRE; e.g., Galarneau et al. 2010; Bosart et al. 2012; Moore et al. 2013), tends to be located 500 $2000 \mathrm{~km}$ away from the TC. Because of the strong latent heat release, a PRE likewise exhibits intense diabatic outflow.

Diabatic outflow of the transitioning TC impinging upon the waveguide may initiate a chain of events that modifies the large-scale midlatitude flow during and following ET. Diabatic outflow by other weather systems such as PREs or extratropical WCBs may act in a similar manner. In this study we demonstrate how a sequence of diabatic outflow events results in a highly amplified midlatitude flow pattern and we contrast the characteristics of diabatic outflow initiated by different weather systems. 
TABLE 1. Characteristics of the 12 western North Pacific September ET cases constituting the composite, the average, and of the control simulation. Shown are the name of the TC, its year of occurrence, its interaction rank (wrt. Archambault et al. 2013, their Table 2), the interaction metric (PVU day ${ }^{-1}$ ), the recurvature-relative time $(\mathrm{h})$ of the maximum TC-midlatitude flow interaction, the recurvature day and hour, the recurvature latitude, the recurvature longitude, the mean sea level pressure $(\mathrm{hPa})$ at the time of recurvature, the maximum sustained winds $\left(\mathrm{m} \mathrm{s}^{-1}\right)$ at time of recurvature, whether the ET system intensified after recurvature, recurvature-relative time (h) of an associated PRE-like feature, and the recurvature-relative time (h) of a downstream WCB. See text for descriptions of how the latter features are identified. Track, MSLP, and MSW are taken from JMA best track data for the individual cases.

\begin{tabular}{|c|c|c|c|c|c|c|c|c|c|c|c|c|}
\hline Name & Year & Rank & Metric & Interaction & Recurvature & Lat $\left({ }^{\circ} \mathrm{N}\right)$ & Lon $\left({ }^{\circ} \mathrm{E}\right)$ & MSLP & MSW & Intensified? & PRE & WCB \\
\hline Oscar & 1995 & 2 & -2.569 & 6 & 0000 UTC 16 Sep & 27.0 & 136.5 & 925 & 51.4 & Yes & -24 & 72 \\
\hline Orchid & 1980 & 6 & -2.308 & 24 & 0000 UTC 10 Sep & 25.5 & 130.0 & 960 & 36.0 & No & 0 & 48 \\
\hline Mireille & 1991 & 9 & -2.149 & 30 & 0600 UTC 26 Sep & 25.5 & 125.5 & 935 & 48.9 & Yes & -6 & 66 \\
\hline Songda & 2004 & 10 & -2.129 & 18 & 0600 UTC 6 Sep & 29.5 & 127.0 & 940 & 41.2 & No & -42 & - \\
\hline Choi-Wan & 2009 & 13 & -2.078 & 24 & 0600 UTC 18 Sep & 24.0 & 139.0 & 950 & 41.2 & No & 6 & 54 \\
\hline Polly & 1995 & 21 & -1.917 & 18 & 1200 UTC 18 Sep & 23.0 & 138.0 & 970 & 33.4 & Yes & 6 & 60 \\
\hline Luke & 1991 & 26 & -1.851 & 36 & 1800 UTC 17 Sep & 23.5 & 129.5 & 985 & 25.7 & Yes & 12 & 108 \\
\hline Gordon & 1982 & 31 & -1.781 & 18 & 0600 UTC 3 Sep & 29.0 & 139.0 & 970 & 33.4 & No & 6 & - \\
\hline Cecil & 1993 & 33 & -1.763 & 12 & 0000 UTC 26 Sep & 24.0 & 144.5 & 950 & 41.2 & Yes & -24 & 60 \\
\hline Judy & 1982 & 34 & -1.762 & 60 & 1200 UTC 9 Sep & 23.0 & 133.5 & 960 & 41.2 & Yes & -18 & 30 \\
\hline Flo & 1990 & 37 & -1.753 & 18 & 0600 UTC 17 Sep & 25.5 & 129.0 & 890 & 61.7 & Yes & -6 & 84 \\
\hline Kinna & 1991 & 39 & -1.747 & 24 & 0000 UTC 13 Sep & 27.0 & 128.0 & 955 & 41.2 & Yes & 0 & 78 \\
\hline Avg & - & - & -1.983 & 24 & - & 25.5 & 133.3 & 949.2 & 41.4 & - & -7.5 & 66.0 \\
\hline Control & - & - & -2.213 & 51 & $T-6 \mathrm{~h}$ & 24.75 & 133.75 & 973.5 & - & Yes & 12 & 102 \\
\hline
\end{tabular}

\section{Data and methodology}

This study is based on 6-hourly NCEP Climate Forecast System Reanalysis (CFSR; Saha et al. 2010) data, which are used to construct composites of selected recurving western North Pacific strong interaction ET cases and which serve as the initial and boundary condition data for numerical simulations with the mesoscale COSMO model (Steppeler et al. 2003). These data are available on a $0.5^{\circ} \times 0.5^{\circ}$ latitude-longitude grid and across 26 pressure levels. For surface parameters not available from CFSR in the layers needed for COSMO (skin and sea surface temperature, soil temperature, soil moisture, snow depth, snow layer temperature), ERAInterim (Dee et al. 2011) data for monthly means at the synoptic times are used. In the following we describe the construction of the composite and initial datasets as well as the diagnostics used.

\section{a. Composites of western North Pacific ET cases}

Composites of 12 western North Pacific ET cases in September are constructed (Table 1, Fig. 1). Each of the 12 cases meets the objective definition of a strong TCextratropical flow interaction (Archambault et al. 2013, their Table 2) based on the magnitude of the spatially and temporally averaged 250-150-hPa-layer averaged negative PV advection by the irrotational wind. As noted in Archambault et al. (2013, 2015), strong interactions tend to be associated with Rossby wave amplification and dispersion across the North Pacific to North America. In the present study, the selection of cases is constrained to September, which is the most active month for western North Pacific ET and specifically for strong interactions. $^{1}$

The 6-hourly three-dimensional meteorological fields are composited relative to both the time of recurvature $(T+0 \mathrm{~h})$ and the location of recurvature following Archambault et al. (2015). That is, the fields are shifted for each case so that recurvature occurs at the mean recurvature location $\left(25.5^{\circ} \mathrm{N}, 133.3^{\circ} \mathrm{E}\right)$. Temporarily, the fields are composited at 6-hourly time steps starting 3 days prior to recurvature $(T-72 \mathrm{~h})$ to 7 days after recurvature $(T+168 \mathrm{~h})$.

\section{b. Composite fields as initial and boundary conditions}

The recurvature-relative composite fields are used as initial and boundary conditions for numerical simulations with the COSMO model. To cover the whole ET process, we initialize the simulations 2 days prior to recurvature $(T-48 \mathrm{~h})$, when the TC is well in its tropical stage. However, at this time the smoothing of the recurvaturerelative composite results in an initial TC vortex that is too weak for the model to spin up to typhoon strength. Therefore, we use an additional TC-relative composite at $T-48 \mathrm{~h}$. From this composite the TC-relative TC in a $20^{\circ} \times 20^{\circ}$ latitude-longitude box is extracted and inserted at the mean location of the TC in the recurvature-relative composite at $T-48 \mathrm{~h}$, yielding a much more realistic TC vortex 2 days prior to recurvature. Within a $4^{\circ}$ boundary

\footnotetext{
${ }^{1}$ Typhoon Thelma (1980) was excluded as it had not formed $72 \mathrm{~h}$ prior to recurvature, and David (1997) and Nabi (2005) were excluded because of data availability issues.
} 
(a) composite tracks

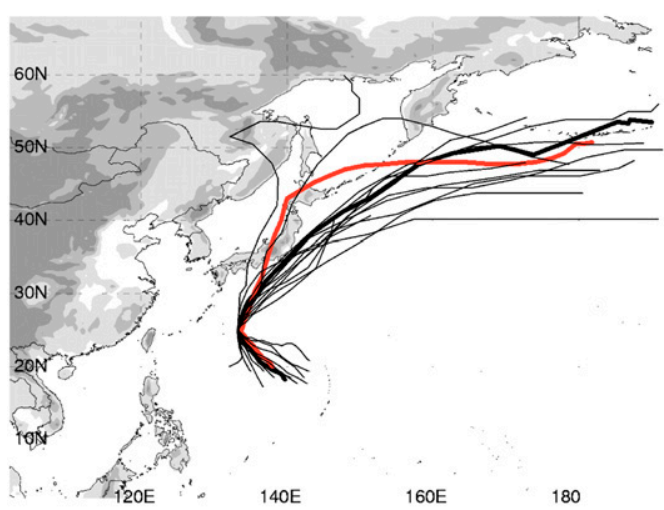

(b) composite center MSLP

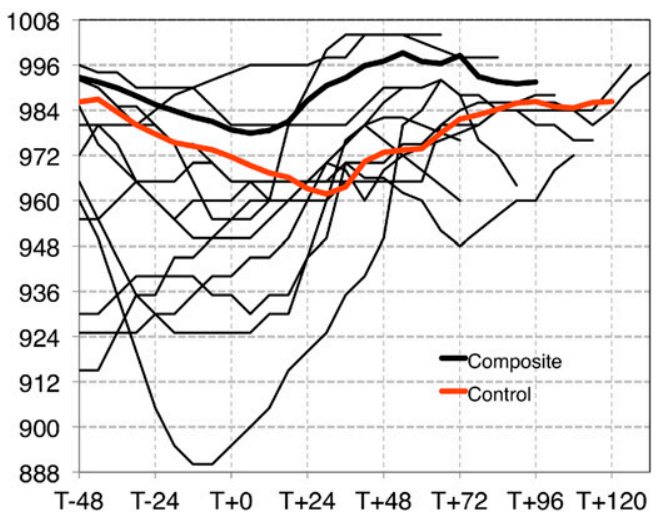

FIG. 1. Characteristics of the control TC (thick red curve, based on MSLP) compared to the composite TC (thick black line, based on MSLP) and 12 individual cases constituting the composite (thin black lines, based on JMA best track data). (a) TC track in the control simulation, the composite, and the individual cases (within a recurvaturerelative framework). Tracks plotted beginning at $T-48 \mathrm{~h}$. (b) TC MSLP (hPa) in the control simulation, composite, and individual cases.

the edges of these boxes are linearly smoothed to achieve a gradual transition to the recurvature-relative environment.

\section{c. Numerical simulations with COSMO}

In this study we use the limited area numerical weather prediction model COSMO (version 4.18; Steppeler et al. 2003), which is in use operationally at many national weather services in Europe (http://cosmo-model.org/) and which is comparable to the Weather Research and Forecasting (WRF) Model. Most physical processes (e.g., subgrid-scale turbulence, radiation) are parameterized following the operational setup. In adaptation to the investigation of ET on large domains we use a Kain-Fritsch scheme (Kain and Fritsch 1993) for the representation of moist convection and a Kessler-type bulk microphysics scheme (Kessler 1969) with six categories of water including water vapor, cloud water, rain, snow, cloud ice, and graupel. We use COSMO instead of WRF because of our technical experience with the TC removal methodology and continuity with earlier studies (Grams et al. 2011, 2013b). However, we note that unlike WRF, COSMO only provides a limited set of different physical parameterizations for sensitivity studies.

Two simulations are performed: a control simulation (CNTRL) initialized from the composite fields described in section $3 \mathrm{~b}$ and a simulation with the $\mathrm{TC}$ removed from the initial conditions (NOTC), using the method described in section $3 \mathrm{~d}$. Following the approach of real-case modeling studies examining the interaction between TCs and the midlatitude flow (Wu and Kurihara 1996; McTaggartCowan et al. 2001; Klein et al. 2002; Agustí-Panareda et al. 2004; Grams et al. 2011, 2013b), we attribute the differences between the two simulations to the impact of the TC on the environmental flow. Except for the initial conditions, both simulations share the same model framework. The model domain extends from $0^{\circ}$ to $78^{\circ} \mathrm{N}$ in latitude and $73^{\circ} \mathrm{E}$ to $4^{\circ} \mathrm{W}$ in longitude at $0.25^{\circ}$ horizontal resolution $(1133 \times 313$ grid points $)$. The choice of $0.25^{\circ}$ is a compromise between having sufficient detail in weather systems of interest and being able to simulate a nearly hemispheric-scale region in order to capture the large-scale development of the large-scale flow pattern. Using such a large domain also avoids the potential for the lateral model simulation boundaries to introduce artifacts into the modeling experiment. In the vertical, 80 levels are used. The simulations are run for $216 \mathrm{~h}$ starting 2 days prior to recurvature $(T-48 \mathrm{~h})$ and ending 7 days after recurvature $(T+168 \mathrm{~h})$. In addition to these two simulations perturbed control simulations are computed to assess the robustness of our ET scenario (see section 4).

\section{d. TC removal technique based on PV surgery}

A PV surgery method is used to remove the TC from the composite fields (Grams et al. 2013b). First, the positive PV anomaly associated with the TC inner core is removed. Second, the modified PV field is inverted using nonlinear balance (Charney 1955; Davis and Emanuel 1991). The output fields of the PV inversion are used to determine anomalies associated with the TC in horizontal wind, temperature, and pressure. Additionally, the anomaly in water constituents (specific humidity, cloud water, cloud ice) associated with the TC is determined based on a threshold approach for each vertical level. The anomalies are subtracted from the model composite fields to remove the storm and vertical velocity in the region of the storm is 
set to zero. This approach allows us to compute the environmental background flow in the region of the TC while leaving the atmospheric conditions in the larger-scale environment unchanged. The results of the PV surgery are illustrated in Fig. S8 and section S3 in the online supplemental material. Details on the method and the specific parameters used in this study are given in Grams et al. (2013b) and in the online supplement to this article, respectively.

\section{e. Metric for the diabatic outflow-extratropical flow interaction}

To assess the magnitude of the diabatic outflowextratropical flow interaction, the instantaneous PV advection by the irrotational wind is computed for each 3-h interval of the COSMO simulations (in PVU h ${ }^{-1}$, where $1 \mathrm{PVU}=10^{-6} \mathrm{~K} \mathrm{~kg}^{-1} \mathrm{~m}^{2} \mathrm{~s}^{-1}$ ). The maximum interaction point is defined as the largest magnitude of instantaneous 250-150-hPa layer-averaged negative PV advection by the irrotational wind over the entire model domain (Archambault et al. 2013, 2015). In addition, for each case forming the composite and for the control simulation, we discuss the value of the TC-extratropical flow interaction metric following Archambault et al. (2013). This metric is defined as the 48 -h temporal average of $\mathrm{PV}$ advection by the irrotational wind (in $\mathrm{PVU}_{\text {day }}{ }^{-1}$ ) centered on the time of maximum interaction as defined above, and spatially averaged for a $15^{\circ} \times 15^{\circ}$ latitude-longitude box centered on the maximum interaction point (Table 1).

\section{f. Trajectory calculations}

Rapidly ascending air parcels are identified with Lagrangian trajectories computed from the threedimensional wind field of the control and no-TC simulation using the Lagrangian Analysis Tool (LAGRANTO) model (Wernli and Davies 1997; Sprenger and Wernli 2015). The trajectories are started in the lower troposphere $(1000-700 \mathrm{hPa}$, every $20 \mathrm{hPa})$ from horizontally equidistant points (horizontal distance is $50 \mathrm{~km}$ ) in the region from $15^{\circ}$ to $60^{\circ} \mathrm{N}$ and $120^{\circ} \mathrm{E}$ to $220^{\circ} \mathrm{E}\left(140^{\circ} \mathrm{W}\right)$, yielding in total 276176 trajectory starting points. The trajectories are restarted every $6 \mathrm{~h}$ from $T-48$ to $T+$ $120 \mathrm{~h}$ and computed forward for $48 \mathrm{~h}$, so that data from nine trajectory calculations are available at each 6-hourly time step. For the computation we use 6-hourly data and trace the location as well as meteorological quantities every $6 \mathrm{~h}$. From the total of $\approx 8 \times 10^{6}$ trajectories, only those are retained that ascend at least $8500 \mathrm{~m}$ $(\sim 600 \mathrm{hPa})$ within the 48 -h period (cf. Grams et al. 2013b). This objective criterion allows us to focus only on air parcels that experience the most vigorous ascent and that are most likely linked to very strong latent heat release (cf. Wernli 1997). A similar criterion has been used by Madonna et al. (2014b) to objectively select the dynamically most active core of rapidly ascending air in WCBs. Trajectories starting in a circle with $600-\mathrm{km}$ radius around the TC center are attributed to the transitioning TC. Trajectories starting in a box extending $5^{\circ}$ west, $15^{\circ}$ east, $5^{\circ}$ south, and $25^{\circ}$ north of the TC center, and not within this circle, are attributed to the PRE. Trajectories ending in the region from $50^{\circ}$ to $75^{\circ} \mathrm{N}$ and $160^{\circ}$ to $110^{\circ} \mathrm{W}$ are attributed to the extratropical WCB in the eastern North Pacific.

\section{g. Quasigeostrophic vertical velocity diagnostic}

For the investigation of the role of the large-scale flow we employ the quasigeostrophic (QG) framework, as in Boettcher and Wernli (2011) and Grams et al. (2013a), that indicates regions favorable for large-scale ascending motion. Based on Clough et al. (1996), the diagnostic allows a height-attributable solution of the QG omega equation in Q-vector form (Hoskins et al. 1978). Following Deveson et al. (2002) and Dacre and Gray (2009), the contribution to the vertical velocity from the upper troposphere $(650-100 \mathrm{hPa})$ is distinguished from the contribution from the lower troposphere (1000-750 hPa) and evaluated at $700 \mathrm{hPa}$. On this level significant vertical motion occurs in extratropical cyclones and contributions from both layers are expected (Deveson et al. 2002; Boettcher and Wernli 2011).

\section{The ET scenario}

The composite-based ET scenario investigated in this study involves three key weather systems: 1) a PRE, 2) a transitioning TC, and 3) a downstream WCB (DSWCB). The three features and their role in midlatitude flow amplification are primarily explored based on a control simulation and the respective no-TC simulation to yield a physically complete picture compared to the raw composite data and to quantify the impact of the transitioning TC on the overall evolution. It is reasonable to question whether the simulations are sensitive to small perturbations in the model and, thus, whether the conclusions are only relevant for this specific ET scenario. Accordingly evidence is presented in support of the argument that the control simulation initialized from composite data is sufficiently representative of the selected western North Pacific ET cases associated with strong interactions by demonstrating the pervasiveness of the aforementioned key weather systems in the composite and an ensemble of COSMO simulations initialized from the composite. A detailed description of the three ET stages associated with each of the three weather systems is contained in section 5. A detailed 
(a) tracks

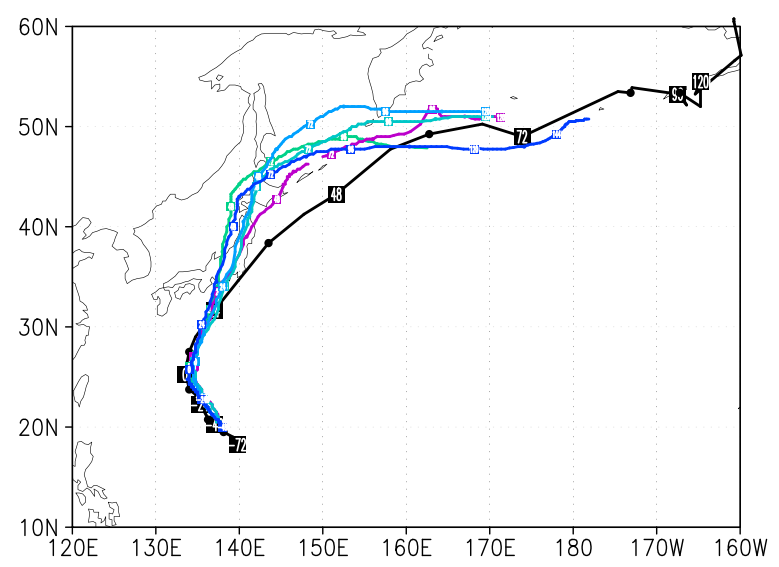

(b) center MSLP

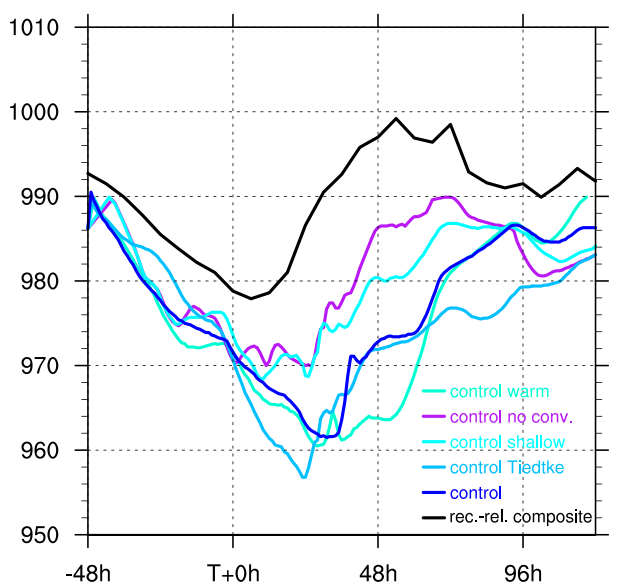

FIG. 2. (a) Track of the recurving TC in the recurvature-relative composite (mean position black solid) and in the control simulations (blue colors) initialized at $T-48 \mathrm{~h}$. Large squares mark 0000 UTC times and are labeled with the time in hours relative to recurvature. Small dots mark 1200 UTC times. (b) Time series of MSLP in the center of the TC for the mean of the recurvature-relative composite (black) and control simulations (blue colors). Labels name the simulations as described in the text.

description of the flow evolution in the composite, control, and no-TC simulation is provided in the online supplemental material (sections S1 and S2).

\section{a. The key features in the composite}

Key characteristics of the 12 September ET cases used for the composite are summarized in Table 1. These overview data are provided as evidence that the control simulation, in which the TC transitions into an intense extratropical cyclone, is preceded by a PRE-like disturbance, and is followed by a DS-WCB, is reasonably representative of the individual cases constituting the composite. The presence of a PRE-like system and DSWCB for each case is established based on visual inspection of relevant fields as detailed in section S6 in the online supplemental material and in the corresponding figures. In 8 of 12 cases, the transitioning TC intensifies after recurvature. All 12 cases show evidence of a PRElike system poleward of the recurving TC that occurs on average $7.5 \mathrm{~h}$ prior to recurvature time, and on average $31.5 \mathrm{~h}$ prior to the maximum TC-extratropical flow interaction. In the control simulation maximum $\mathrm{TC}-$ extratropical flow interaction occurs in a comparable period after the PRE $(39 \mathrm{~h})$. For all cases also the strongest interaction in terms of negative PV advection by irrotational wind is related to the diabatic outflow by the actual transitioning TC. Ten of the 12 cases are found to be followed by a DS-WCB.

A comparison of the CNTRL TC track to the tracks of the 12 individual TCs within the composite (Fig. 1a) reveals that the CNTRL TC track is within the envelope of individual TC tracks throughout, and is nearly identical to the composite TC track between $T-48$ and $T+24 \mathrm{~h}$. The control TC recurves at almost the same location and time as the composite mean, a noteworthy result given that, apart from the initial conditions and lateral boundaries, the simulation is unconstrained. Between $T+24$ and $T+72 \mathrm{~h}$, the CNTRL TC track is near the northern edge of the track envelope, but is again close to the composite TC track after $T+72 \mathrm{~h}$. Thus, the CNTRL TC track overall is deemed reasonably representative of the TCs tracks in the cases constituting the composite. A check of the intensity of the CNTRL TC against that of the individual TCs in terms of MSLP (Fig. 1b) indicates that the intensity of the CNTRL TC is representative of the individual cases in the composite, as it is well within the ensemble envelope of TC intensity throughout. Given that the control track is from model data with $0.25^{\circ}(\approx 28 \mathrm{~km})$ horizontal resolution, one would not necessarily expect TC intensities to be as strong as in the JMA best track dataset.

\section{b. Robustness of the model simulations}

To assess the sensitivity of the ET scenario to perturbations in the model setup, we perform additional control simulations. Namely, we test different schemes for the parameterization of moist convection and microphysics, as both directly influence latent heat release and thus diabatic outflow. The additional simulations are run: a control simulation using a Tiedtke mass flux scheme (Tiedtke 1989) for the representation of moist convection (control Tiedtke), one using the Tiedtke scheme for shallow clouds only (control shallow), one with convective parameterization completely switched 


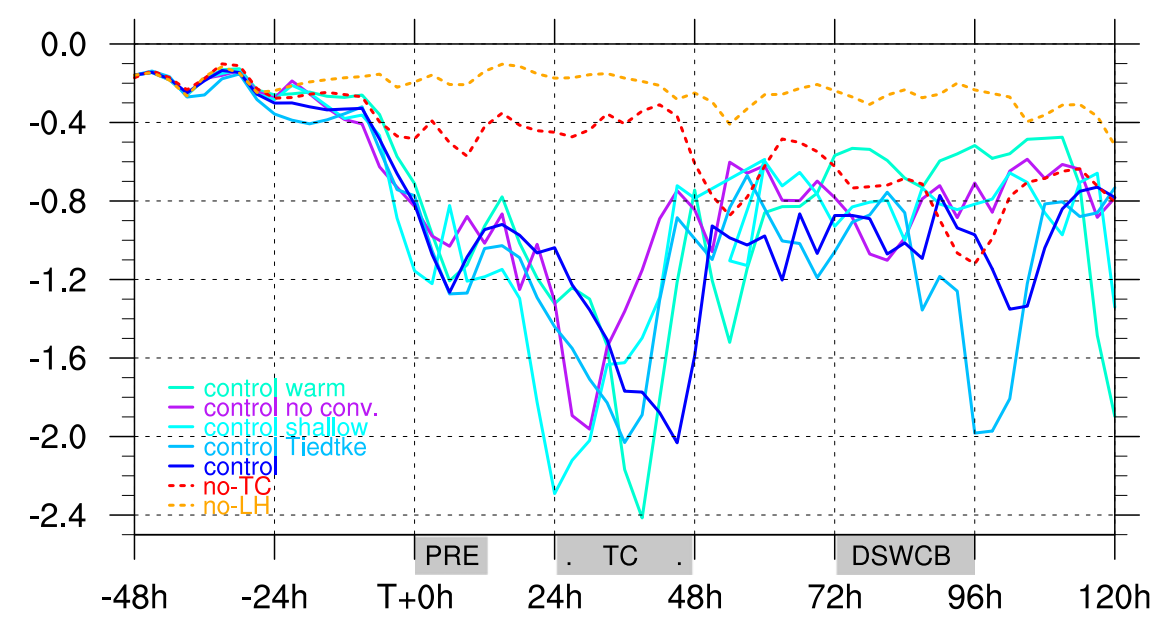

FIG. 3. Time series of maximum interaction in the COSMO simulations as labeled. Shown is the instantaneous minimum value of negative $\mathrm{PV}$ advection by the irrotational wind $\left(\mathrm{PVU} \mathrm{h}^{-1}\right.$, $y$ axis) at a grid point in the domain covering the entire Pacific $\left(10^{\circ}-75^{\circ} \mathrm{N}, 110^{\circ} \mathrm{E}-100^{\circ} \mathrm{W}\right)$ over time. The $x$ axis shows the recurvature-relative time in hours. Periods for the occurrence of a PRE, TC, and DS-WCB are indicated. See text for details and Fig. 5 for the weather systems mentioned.

off (control no conv.), and one using the Kain-Fritsch scheme but microphysics only for gaseous and liquid phases of water (control warm).

The tracks and center MSLP of the transitioning TCs of all five control simulations and of the composite mean are shown in Fig. 2. In general, all control simulations have a similar track, recurve at the same location and time, and track bifurcation does not occur until $T+24 \mathrm{~h}$ (Fig. 2a). However, differences exist in the intensity of the transitioning TC with the simulation with no convective or only shallow convective parameterization exhibiting the weakest cyclones. The simulation with Tiedtke parameterization exhibits the most intense cyclone and most poleward track.

To discuss the (non)existence of the PRE, transitioning TC, and DS-WCB, we show a time series of the maximum interaction in terms of negative PV advection by the irrotational wind in the North Pacific region $\left(10^{\circ}-75^{\circ} \mathrm{N}\right.$, $110^{\circ}-260^{\circ} \mathrm{E}$; Fig. 3). If the diabatic outflow associated with each of the three key weather systems strongly impinges on the waveguide and helps in amplifying the midlatitude Rossby wave pattern, we expect periods of local minima in this time series. Indeed, all control simulations exhibit local minima of negative PV advection by the irrotational wind (Fig. 3, bluish curves) during the respective period (PRE, $T+0$ to $T+12 \mathrm{~h}$; TC, $T+24$ to $T+48 \mathrm{~h}$; DS-WCB, $T+72$ to $T+96 \mathrm{~h}$ ) and region, and are directly linked to the key weather systems at the respective times (cf. Figs. 4 and 5). Despite a qualitatively similar picture, the control simulations exhibit some differences about the exact timing and intensity of the PRE, $\mathrm{TC}$, and DS-WCB interactions.
The no-TC simulation (Fig. 3, red dashed) exhibits only weak interaction until $T+48 \mathrm{~h}$. Albeit weaker than in the control simulation, notable magnitudes of negative PV advection occur later in the simulation, and are due to a weaker DS-WCB that occurs in the absence of ET but results in a much less amplified downstream ridge (see below).

We consider the no-TC simulation to be representative of the scenario in which the most dynamically relevant diabatically driven weather systems (i.e., the PRE, TC, and strong DS-WCB) are absent or substantially weakened. Despite the fact that only the TC has been removed from the initial conditions, the amplification of a Rossby wave is less pronounced, and the PRE and DS-WCB are almost absent, consistent with a lack of strong meridional moisture flux (section S2 and Figs. S7b,d,f in the online supplemental material). To demonstrate the intrinsic diabatic nature of the PRE, transitioning TC, and DS-WCB, along with their importance in Rossby wave amplification, an additional simulation has been computed. This simulation (no LH) shares the same setup as control Tiedtke, but the latent heat release (LHR) due to phase transitions is set to zero. Lacking LHR, the TC decays, no PRE or strong DSWCB exists, and diabatic outflow by these weather systems are absent (not shown). This is reflected in the weak negative PV advection by the irrotational wind in this simulation (Fig. 3, orange dashed).

\section{c. Downstream flow evolution in the ET scenario}

The evolution of the upper-level midlatitude flow in the recurvature-relative composite mean, control, no-TC, and no-LH simulations is discussed with the help of a spaghetti diagram of geopotential height at $200 \mathrm{hPa}$ 

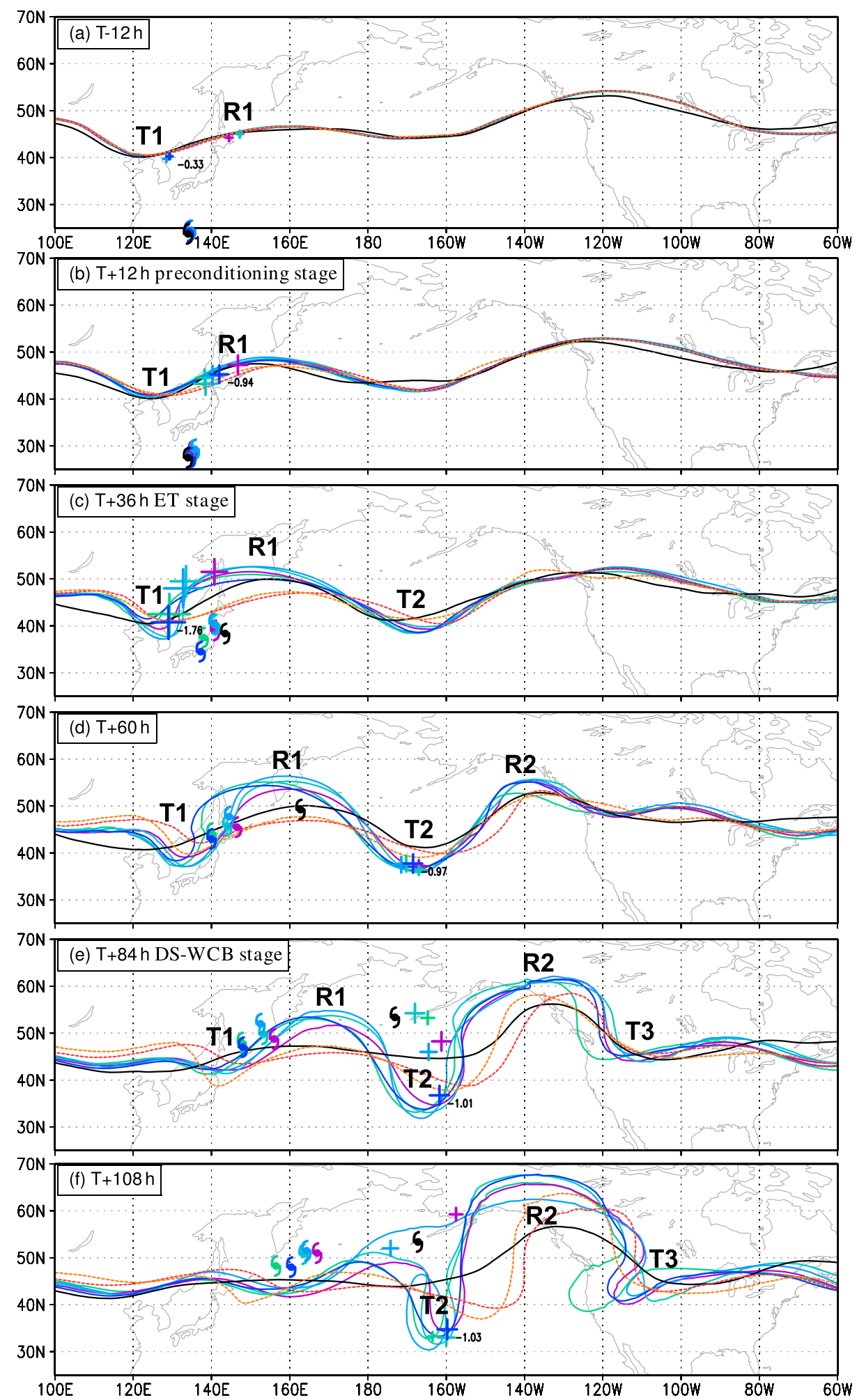

FIG. 4. Geopotential height at $200 \mathrm{hPa}$ (1200-dam contour) for the recurvature-relative composite (black), the control simulations (bluish solid, as in Fig. 2), and the no-TC (red dashed) and no-LH (orange dashed) experiments shown every $24 \mathrm{~h}$ starting $12 \mathrm{~h}$ prior to recurvature $(T-12 \mathrm{~h}$ ). The TC symbols mark the position of the transitioning TCs in the composite (black) and control simulations (blue colors). The plus sign marks the location of the maximum interaction point (in terms of negative PV advection by irrotational wind) in the entire domain for the control simulations (values given for control, in $\mathrm{PVU} \mathrm{h}^{-1}$ ). Trough and ridge axes are labeled. See section 4 for details on the simulations. 
(a) CNTRL T+6 h (preconditioning stage)

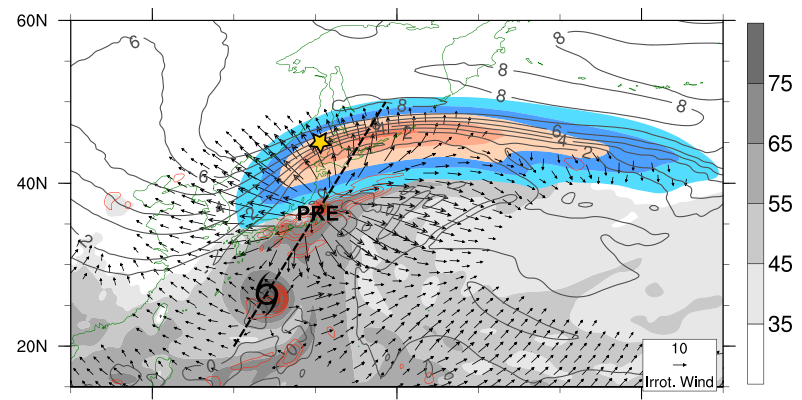

(b) CNTRL T+45 h (ET stage)

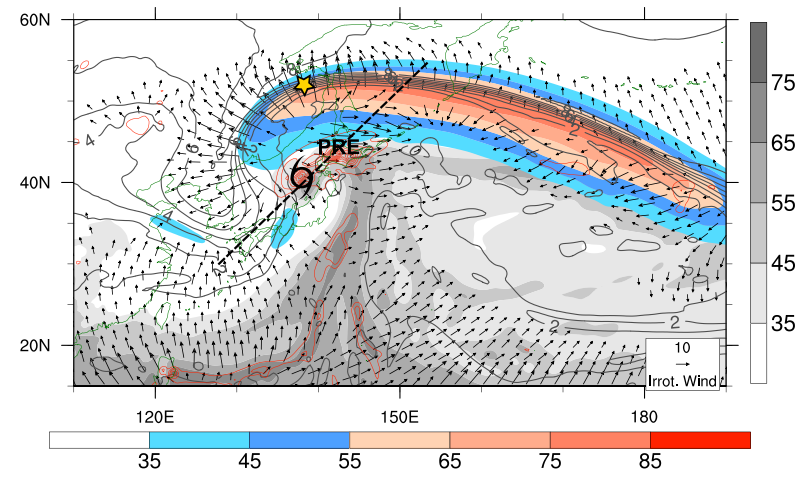

(c) CNTRL T+87 h (DS-WCB stage)

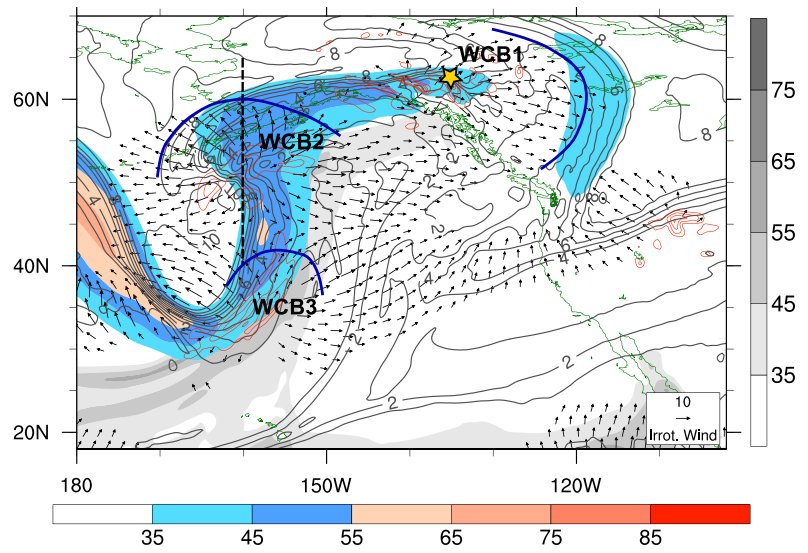

FIG. 5. Wind speed (color shading in $\mathrm{m} \mathrm{s}^{-1}$ ), PV (gray contours every 1 PVU), and irrotational wind (vectors $>5 \mathrm{~m} \mathrm{~s}^{-1}$ ) vertically averaged at jet level $(250-150 \mathrm{hPa})$. Also shown are the midlevel ascent $\left(600-400 \mathrm{hPa}\right.$; red contours every $-5 \times 10^{-3} \mathrm{hPa}^{-1}$ and the vertically integrated precipitable water column (gray shading in $\mathrm{mm}$ ). The dashed line indicates the location of the cross sections shown in Fig. 8. The TC symbol shows the approximate location of the TC, the PRE label shows the PRE, and the yellow star indicates the location of the maximum interaction point. See text and section $3 \mathrm{e}$ for details of the computation. Times shown are (a) $T+6$, (b) $T+45$, and (c) $T+87 \mathrm{~h}$. Note that (a),(b) show the western North Pacific domain and (c) shows the eastern North Pacific domain.
(Fig. 4). At $T-12 \mathrm{~h}$, hardly any difference exists between the model simulations (Fig. 4a) and only weak interaction with the midlatitude flow occurs (less than $-0.3 \mathrm{PVU} \mathrm{h}^{-1}$ ). The TC is located at about $24^{\circ} \mathrm{N}, 134^{\circ} \mathrm{E}$ ahead of an initial midlatitude trough (T1) to the northwest and a weak ridge to the west (R1).

One day later the impact of the PRE diabatic outflow becomes evident. While ridge $\mathrm{R} 1$ amplifies in the control simulations (Fig. 4b, bluish solid) and composite, the noTC and no-LH experiments show a much less amplified flow (Fig. 4b, reddish dashed). Relatively strong minima in negative PV advection by the irrotational wind (less than $-0.9 \mathrm{PVU} \mathrm{h}^{-1}$ ) are confined to the region of the PRE. Farther downstream, no differences exist between the control, no-TC, and no-LH simulations, reflecting the absence of weather systems with strong LHR at that time. Note that the model simulations are only constrained by the lateral boundaries, explaining the differences to the composite mean after $60 \mathrm{~h}$ of model integration.

During the next two days the TC undergoes ET ahead of trough T1 and a strong ridge builds northwest of Japan (R1) in all control simulations. At $T+36 \mathrm{~h}$, very strong minima in negative $\mathrm{PV}$ advection by the irrotational wind $\left(-1.3\right.$ to $\left.-2.1 \mathrm{PVU} \mathrm{h}^{-1}\right)$ occur on the upstream flank of ridge $\mathrm{R} 1$ as a result of the interaction of the transitioning TC with the midlatitude flow (Figs. $4 \mathrm{c}$ and 3 ). The troughridge couplet T1-R1 further amplifies in the control simulations and the composite mean, behavior that is not evident in the no-TC and no-LH simulations. At $T+60 \mathrm{~h}$, the ridge building of $\mathrm{R} 1$ directly downstream of the transitioning TC peaks in all of the control simulations. Likewise, a pronounced downstream Rossby wave packet amplifies with a downstream trough (T2) in the central Pacific and a downstream ridge (R2) in the east Pacific (Fig. 4d, bluish solid). Minima in negative PV advection by irrotational wind shift to the tip of $\mathrm{T} 2$ (less than $-0.6 \mathrm{PVU} \mathrm{h}^{-1}$ ) and are linked to incipient downstream WCB activity (cf. section 5). The flow is much less amplified in the no-TC and no-LH simulations, although a downstream trough-ridge couplet (T2-R2) also emerges, reflecting the predominant dry dynamic component of downstream development triggered by the initial Rossby wave packet (T1-R1).

A 2-day period of repeated WCB activity in the eastern North Pacific results in strongly amplified flow over the eastern North Pacific-North American region (Figs. 4e,f). At $T+84 \mathrm{~h}$ strong negative PV advection by irrotational wind on the upstream flank of ridge R2 (up to $-1.0 \mathrm{PVU} \mathrm{h}^{-1}$ ) reflects the interaction of WCB diabatic outflow with the upper-level waveguide, broadening and amplifying ridge $\mathrm{R} 2$ (see Fig. $4 \mathrm{e}$ and the discussion in section 5b). At $T+108 \mathrm{~h}$, four of the five 
control simulations exhibit a strongly amplified downstream ridge $\mathrm{R} 2$ extending poleward of $65^{\circ} \mathrm{N}$ (Fig. 4f, bluish solid), while anticyclonic Rossby wave breaking has already occurred in the control Tiedtke simulation (light blue), reflected in a broad and more zonally oriented ridge (R2). This is consistent with the very strong TC, most poleward TC track (cf. Fig. 2), and prolonged period of intense (less than $-1.6 \mathrm{PVU} \mathrm{h}^{-1}$ ) TC-extratropical flow interaction in the control Tiedtke simulation (cf. Fig. 3). All control simulations indicate the breaking of a second downstream trough (T3). Although ridge $\mathrm{R} 2$ and trough $\mathrm{T} 3$ are present in the no- $\mathrm{TC}$ and no-LH simulations, their amplitude and spatial extent are much smaller. Likewise, R2 and T3 are located farther eastward, corroborating previous findings that ET tends to hinder the eastward propagation of Rossby wave packets (Riemer et al. 2008; Quinting and Jones 2016). Note that the downstream ridge $R 2$ is also evident in the composite mean, consistent with its presence in all 12 cases constituting the composite.

Based on the foregoing demonstration of the robustness of key features surrounding western North Pacific strong ET, our experience simulating ET with COSMO, and recommendations by DWD (A. Seifert 2015, personal communication), we continue our study using the COSMO setup with the Kain-Fritsch convection scheme and six-water-category microphysics (control and no TC). A further discussion of the other simulations is beyond the scope of this paper. A thorough investigation of the no- $\mathrm{LH}$ experiment is the topic of ongoing work.

From this section we conclude the following. 1) The control simulation is a sufficiently representative scenario for western North Pacific ET cases associated with strong TC-extratropical flow interactions. 2) During and following the ET event a pronounced Rossby wave packet is triggered. 3) This important midlatitude flow amplification occurs in three distinct stages, with each involving diabatic outflow from strong latent heat release in different weather systems: a PRE, the transitioning TC, and a downstream WCB. In the following the nature and impact of these diabatic outflow will be explored in detail.

\section{Details of the midlatitude impact of ET}

The previous section included evidence of three important stages of the investigated western North Pacific strong interaction ET scenario. 1) At an early stage of ET, the diabatic ridge building by a PRE initially amplifies the upper-level flow, a process that can be regarded as preconditioning for the interaction of the TC itself with the midlatitude flow ("preconditioning (a) CNTRL-NOTC $\mathbf{T}+\mathbf{1 2} \mathbf{h}$ (preconditioning stage)

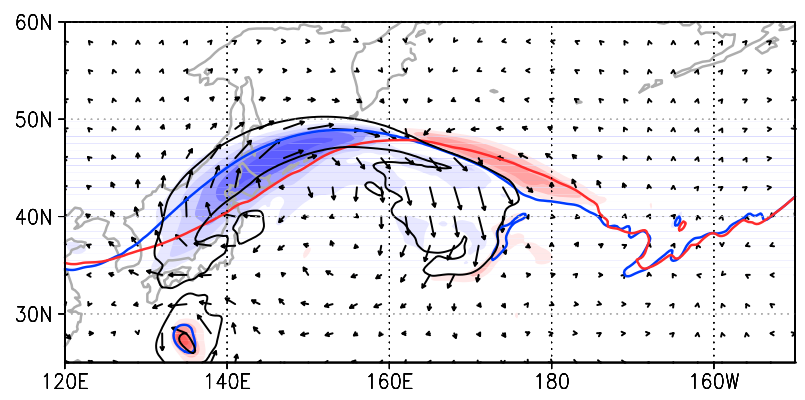

(b) CNTRL-NOTC $\mathbf{T}+\mathbf{3 6} \mathbf{h}$ (preconditioning stage)

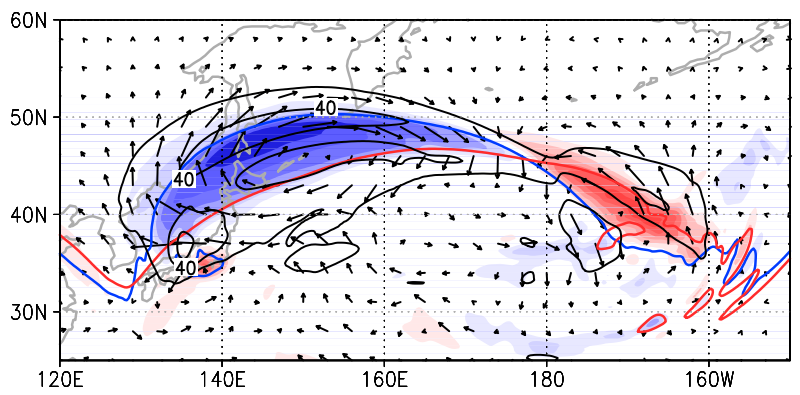

(c) CNTRL-NOTC T+60 h (ET stage)

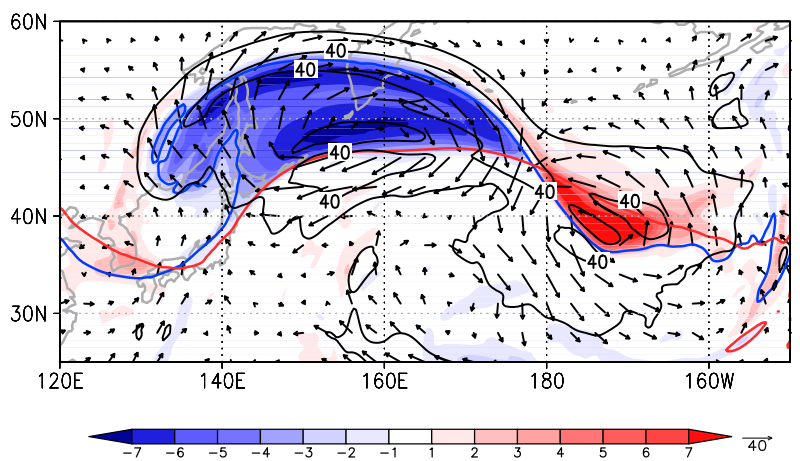

FIG. 6. Difference (CNTRL - NOTC) of PV (shaded in PVU), wind vector difference (magnitude, black contours every $20 \mathrm{~m} \mathrm{~s}^{-1}$ for $>20 \mathrm{~m} \mathrm{~s}^{-1}$ and black vectors), and 3-PVU contour (blue, CNTRL; red, NOTC) at the $345-\mathrm{K}$ isentropic level. Times shown are (a) $T+12$, (b) $T+36$, and (c) $T+60 \mathrm{~h}$.

stage"). 2) The ET of the TC builds a ridge and triggers a downstream Rossby wave packet ("ET stage"). 3) Later, strong downstream ridge building occurs in the eastern North Pacific in conjunction with a sequence of extratropical WCBs ["downstream WCB (DS-WCB) stage"].

In the next two sections we show more evidence of these different diabatically driven weather systems and corroborate our notion that the diabatic outflow associated with each act in a similar sequence of physical processes to overall amplify the midlatitude flow. Here, we document this key sequence of physical processes in 
more detail for the preconditioning stage and less detail for the ET and DS-WCB stages, employing an Eulerian perspective. The picture is complemented by contrasting Lagrangian flow characteristics in section 6 .

\section{a. The direct impact of ET}

A first midlatitude flow amplification occurs as a result off the diabatic outflow of a PRE and of the transitioning TC and is manifested in the amplification of the first trough-ridge couplet (T1-R1; cf. Figs. 4a-d) during the period up to about 3 days after recurvature $(T+72 \mathrm{~h})$.

\section{1) THE ROLE OF A PREDECESSOR RAIN EVENT}

The signature of a PRE is prominent at $T+6 \mathrm{~h}$, reflected in a region of very high total precipitable water (gray shades) collocated with a maximum of ascent (red contours) at about $37^{\circ} \mathrm{N}, 140^{\circ} \mathrm{W}$ (Fig. 5a). Above the PRE, strong divergent outflow expands axisymmetrically over a broad region and, importantly, over the western flank of the building ridge. At this time, the divergent outflow associated with the TC is confined to levels above $150 \mathrm{hPa}$ (see discussion of Fig. 8a below). The divergent PRE outflow impinges almost perpendicular to the midlatitude waveguide, reflected in dense PV isolines (gray contours), enhancing the upper-level PV gradient and intensifying a jet streak. The cross-PV gradient outflow is maximized to the north of the PRE at about $43^{\circ} \mathrm{N}, 139^{\circ} \mathrm{W}$, where strongest interaction occurs $\left(-1.3 \mathrm{PVU} \mathrm{h}^{-1}\right.$; Figs. 3 and 5a).

The initial ridge amplification by PRE outflow is reflected in a negative anomaly $(\triangle \mathrm{PV}<-4 \mathrm{PVU})$ of the $\mathrm{PV}$ difference on the isentropic $345-\mathrm{K}$ level between CNTRL and NOTC $(T+12 \mathrm{~h}$; Fig. $6 \mathrm{a})$. In the no-TC simulation the PRE is absent as a result of the lack of strong meridional moisture transport by the lowertropospheric TC circulation (cf. Figs. S6a, S7a, and section S2 in the online supplemental material). The negative PV anomaly is confined to the western flank of ridge $\mathrm{R} 1$ where the diabatic outflow by the PRE amplifies the ridge poleward while the TC is still located farther equatorward, at about $27^{\circ} \mathrm{N}, 135^{\circ} \mathrm{E}$ (Fig. 6a; cf. Figs. 5a and S10f,g in the online supplemental material). The ridge strongly amplifies ( $\triangle \mathrm{PV}<-7 \mathrm{PVU})$ during the next $24 \mathrm{~h}(T+36 \mathrm{~h}$; Fig. $6 \mathrm{~b})$, along with the gradually increasing impact of the diabatic outflow of the transitioning TC. Likewise, the upstream trough $\mathrm{T} 1$ amplifies and the jet accelerates (Figs. 6a,b).

The initial interaction of the PRE outflow with the upper-level midlatitude waveguide is associated with large-scale midlatitude forcing for midlevel ascent by the gradually amplifying trough-ridge couplet [T1-R1; cf. very weak QG ascent $36 \mathrm{~h}$ before recurvature (Fig. 7a) and a (a) CNTRL-NOTC T-36 h

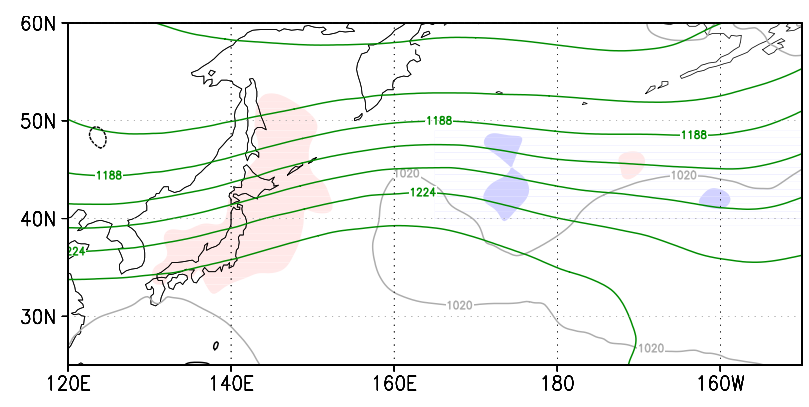

(b) CNTRL-NOTC $\mathbf{T}+\mathbf{1 2} \mathbf{h}$ (preconditioning stage)

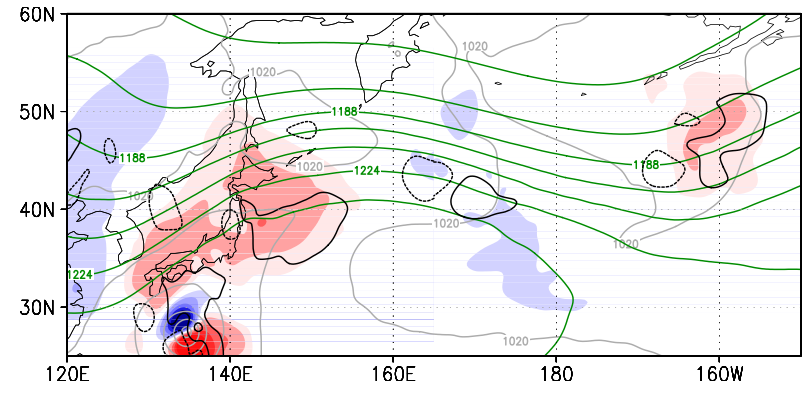

(c) CNTRL-NOTC T+60 h (ET stage)

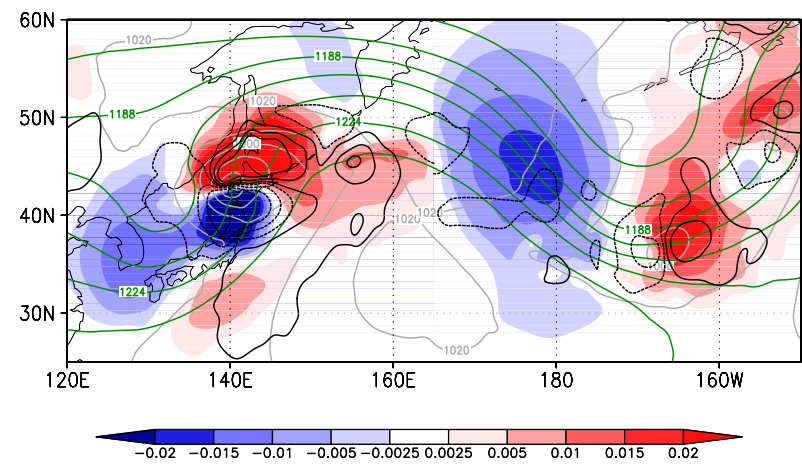

FIG. 7. QG contribution to vertical velocity on $700 \mathrm{hPa}$ from upper levels $\left(<650 \mathrm{hPa}\right.$, shaded in $\left.\mathrm{m} \mathrm{s}^{-1}\right)$ and lower levels $(1000$ $750 \mathrm{hPa}$; black contours for $0.0025,0.01$, and $0.02 \mathrm{~m} \mathrm{~s}^{-1}$; solid for positive values and dashed for negative values). MSLP (gray contours, every $10 \mathrm{hPa}$ ) and 200-hPa geopotential height (green contours $\leq 1236 \mathrm{dam}$, every $12 \mathrm{dam}$ ) are also shown. Data shown for the CNTRL simulation (a) $36 \mathrm{~h}$ prior to recurvature and (b) 12 and (c) $60 \mathrm{~h}$ after curvature. See text and section $3 \mathrm{~g}$ for details of the computation.

broad region of QG ascent $12 \mathrm{~h}$ after recurvature (Fig. 7b)], which is absent in the no-TC simulation (not shown).

A cross section through the TC and PRE at the time of maximum interaction of PRE outflow and the upperlevel midlatitude waveguide $(T+6 \mathrm{~h}$; Figs. $8 \mathrm{a}$,b) highlights the TC inner core with high $\mathrm{PV}$ values (PV $>$ $2 \mathrm{PVU})$ and a warm core $\left(\Theta_{e}>350 \mathrm{~K} ; 800 \mathrm{~km}\right.$ along the $x$ axis; Fig. 8a). The upper-level TC outflow is reflected in low PV values at levels above $200 \mathrm{hPa}$ and has a prominent equatorward branch $(300-700 \mathrm{~km}$; Fig. $8 \mathrm{a})$. To the 

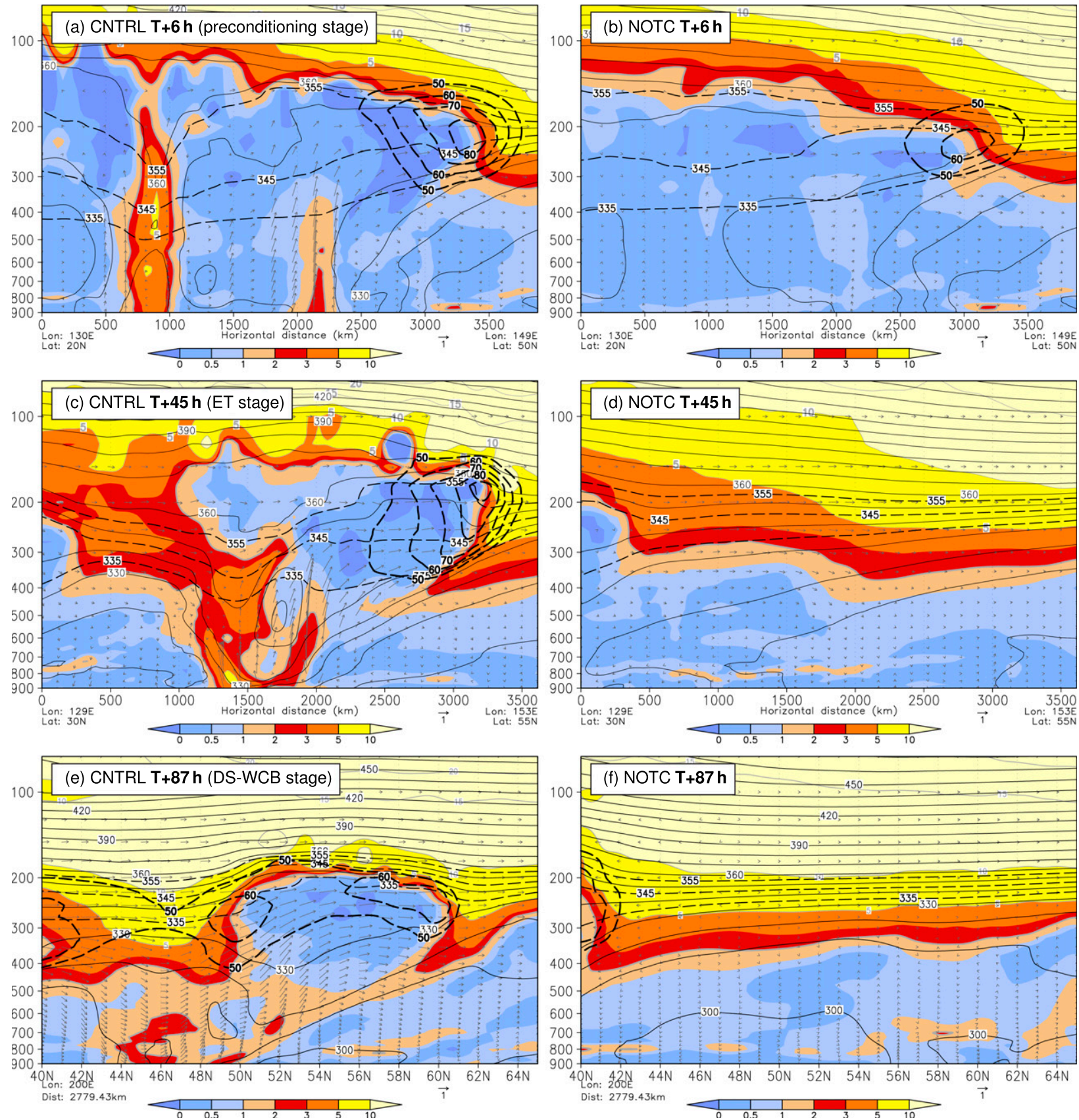

FIG. 8. Cross section of PV (shaded in PVU), equivalent potential temperature (black thin contours every $10 \mathrm{~K}$ ), potential temperature (black thick dashed 335-, 345-, and 355-K contours), horizontal wind speed (black thick dashed contours every $10 \mathrm{~m} \mathrm{~s}^{-1}$ starting $>50 \mathrm{~m} \mathrm{~s}^{-1}$ ), and wind vectors (gray, qualitatively showing direction). The horizontal location of the cross section is indicated in (a), (b) for Fig. 5a, (c),(d) for Fig. 5b, and (e),(f) for Fig. 5c. Data taken from (a),(c),(e) CNTRL and (b),(d),(f) NOTC and at the time of the maximum interaction of the PRE/ET/WCB outflow and the jet $[T+6, T+45$, and $T+87 \mathrm{~h}$ for (a),(b); (c),(d); and (e),(f), respectively]. See text for details.

north of the TC, the midlatitude baroclinic zone is consistent with an enhanced horizontal $\Theta_{e}$ gradient in the lower half of the troposphere $(2300-2700 \mathrm{~km}$; Fig. 8a). The low-level TC circulation advects tropical warm, moist air against the baroclinic zone (cf. total precipitable water in Fig. 5a), where vertically deep ascent occurs in the lower half of the troposphere that becomes more slantwise along the (moist) isentropes at upper levels. This ascent is supported by upper-level forcing (cf. Fig. 7b), which is characteristic of PRE 
convection. Latent heat release (not shown) results in diabatically produced positive PV at lower levels just ahead of the baroclinic zone and marks the center of the PRE (2200 km; Fig. 8a). Above the maximum of latent heating, PV is diabatically reduced, and advected upand poleward by the PRE outflow $(2300-3300 \mathrm{~km})$, yielding an effective redistribution of the strongly diabatically influenced low-PV air $(\mathrm{PV} \approx 0 \mathrm{PVU})$ in the region of the amplifying ridge. The injection of low-PV air in the upper-isentropic layer sharpens the tropopause PV gradient, lifts the tropopause to about $180 \mathrm{hPa}$, and results in a prominent tropopause fold at the poleward edge of the outflow $(3300 \mathrm{~km})$. A jet streak evolves in the region of the maximum tropopause PV gradient at the fold.

Although a baroclinic zone is present in the absence of the TC (2300-2700 km along the $x$ axis; Fig. 8b), neither the TC nor a PRE occurs. Lacking the diabatically enhanced transport of low-PV air to the tropopause, the $\mathrm{PV}$ gradient is weaker, the tropopause lower, and no sharp tropopause fold and or strong jet streak forms.

The initial ridge building and lifting of the tropopause due to the PRE diabatic outflow north of the transitioning TC can be regarded as an important preconditioning of the upper-level flow for extratropical development. The amplified flow in response to the PRE outflow favors stronger dynamical forcing and more intense latent heat release owing to the enhanced poleward transport of warm moist air, thus creating a more favorable environment for baroclinic development over the region into which the transitioning TC is moving. This key sequence of physical processes amplifying the midlatitude flow continues along with the diabatic outflow of the transitioning TC and occurs again later farther downstream along with WCB outflow.

\section{2) RIDGE BUILDING BY THE TRANSITIONING TC}

During the next 2 days, the impact of PRE outflow on the midlatitude flow is gradually replaced by a similar interaction of the transitioning TC with the midlatitude flow. Such an interaction of a transitioning TC with the midlatitude flow has previously been described in detail by different authors (e.g., Bosart and Lackmann 1995; Atallah and Bosart 2003; Torn 2010; Grams et al. 2013b; Archambault et al. 2015).

At $T+45 \mathrm{~h}$ strong diabatic outflow by the transitioning TC (located at about $40^{\circ} \mathrm{N}, 138^{\circ} \mathrm{E}$; Fig. 5b) further amplifies the first trough-ridge couplet (T1$\mathrm{R} 1$ ) and results in an absolute minimum of negative PV advection by the irrotational wind of $-2.0 \mathrm{PVU} \mathrm{h}^{-1}$ (Figs. 3, 5b; Fig. S9a). Neither a pure TC nor a PRE signature is evident, indicating that the two weather systems merge (Fig. 5b).
The continuing flow amplification and jet acceleration directly downstream of the transitioning TC are confirmed in prominent negative difference PV of widely below $-5 \mathrm{PVU}$ and strong difference wind speeds of more than $40 \mathrm{~m} \mathrm{~s}^{-1}(T+60 \mathrm{~h}$; Fig. $6 \mathrm{c}$; cf. Figs. $4 c$ and $4 d$ ). Farther downstream, a positive difference $\mathrm{PV}$ of above $7 \mathrm{PVU}$ reflects the amplification of the downstream trough (T2) in the presence of ET (Fig. 6c). The dipoles of strong upper-level and lower-level QG ascent reflect the effects of differential vorticity advection at upper levels and differential temperature advection at low levels (Fig. 7c). Farther downstream, QG ascent increases ahead of amplifying trough T2.

The vertical cross section indicates the merging of the remnants of the TC inner core $(1400 \mathrm{~km}$; Fig. $8 \mathrm{c})$ with the PRE ahead of the now much stronger lowlevel baroclinicity $(1700 \mathrm{~km}$; Fig. $8 \mathrm{c})$. At upper levels the remnant positive $\mathrm{PV}$ anomaly of the TC inner core merges with the approaching upstream trough (3001100 km; Fig. 8c).

On the poleward side of the merger system ascent becomes more slantwise along the moist isentropes (1800-3000 km; Fig. 8c). This reflects the gradual transition from convective, upright ascent during the tropical stage of the TC and in the PRE to more slantwise ascent in the evolving warm sector of the merger system, and the evolution of a WCB-like airstream (cf. Figs. S2, S6, and section $\mathrm{S} 2$ in the online supplemental material). Diabatic outflow and associated ridge building are maintained, resulting in a further lifting of the tropopause to about $150 \mathrm{hPa}$ and an intensification of the jet streak.

In contrast none of this behavior is present in the noTC simulation, and tropopause height is as low as about $300 \mathrm{hPa}$ (Fig. 8d). Note that the interaction of the ET and PRE with the midlatitude flow also results in an amplification of the upstream trough (T1), reflected in a reduced tropopause height of about $380 \mathrm{hPa}$ below the trough $(500 \mathrm{~km}$; Fig. $8 \mathrm{c})$, compared to about $300 \mathrm{hPa}$ when the interaction does not occur (Fig. 8d).

In summary, the combined effect of PRE and TC/ET outflow results in several days of ridge building directly to the northeast of the transitioning TC, leading to the triggering and downstream dispersion of Rossby waves. No sharp boundary exists between the preconditioning and ET stages. Rather, a gradual transition from PREdominated to TC/ET-dominated outflow translates into a continuous upper-level Rossby wave forcing by diabatic outflow over the western North Pacific [illustrated with a time series in Figs. S10c $(T-12 \mathrm{~h})$ to S11f $(T+66 \mathrm{~h})$ and the animations in the online supplemental material]. 


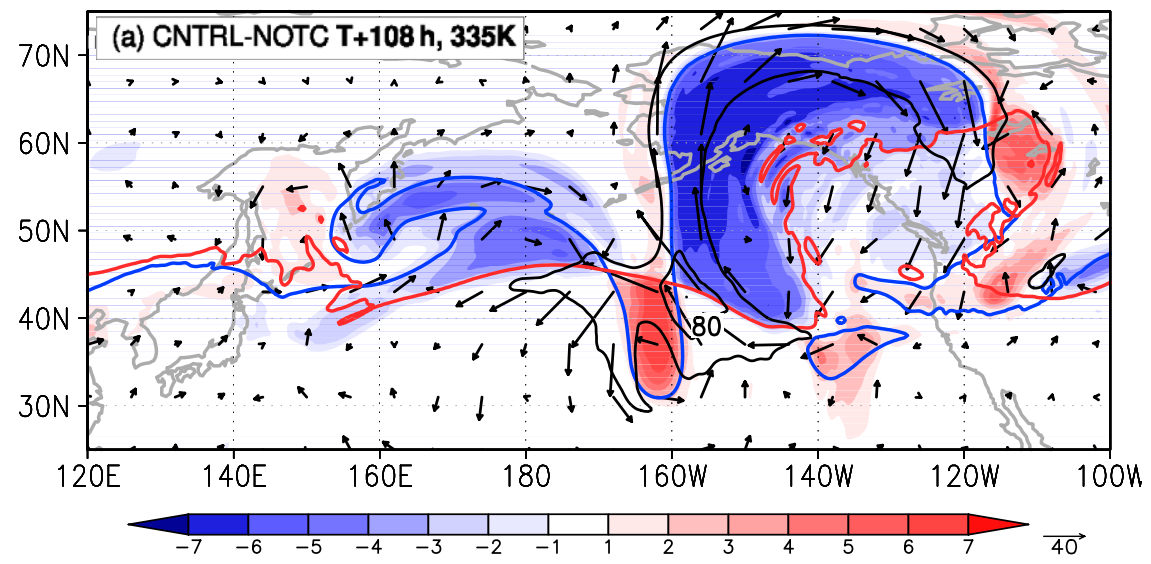

FIG. 9. Difference in PV and wind as in Fig. 6, but for data shown at the 335-K isentropic level and at $108 \mathrm{~h}$ after recurvature, during the "downstream WCB stage" of ET. Difference wind speed magnitude is shown every $40 \mathrm{~m} \mathrm{~s}^{-1}$ for $>40 \mathrm{~m} \mathrm{~s}^{-1}$.

\section{b. The downstream impact of ET}

Downstream development and midlatitude flow modification occur in the eastern North Pacific (T2-R2; cf. Figs. 4c and 4f) in the period 3-7 days after recurvature $(T+72$ to $T+168 \mathrm{~h})$. This period is characterized by extratropical cyclogenesis in the eastern North Pacific and continuous WCB activity. Here, we discuss the characteristics of the resulting downstream upper-level ridge (R2), at its initial and fully amplified stages.

The difference in PV at the isentropic 335-K level shows a very prominent ridge over the eastern North Pacific and Alaska at $T+108 \mathrm{~h}[\Delta \mathrm{PV}<-7 \mathrm{PVU}$ (Fig. 9); R2 in Fig. 4f; cf. Figs. S2d and S3d]. Note that this ridge (R2) is only apparent at the lower $335-\mathrm{K}$ level. The ridge directly downstream of the transitioning TC (R1) is still evident (but weaker at $335 \mathrm{~K}$ ) in the western North Pacific ( $\Delta$ PV $<-3$ PVU; Fig. 9). The elongation of downstream trough $\mathrm{T} 2$ is reflected in the high positive difference $\mathrm{PV}(\Delta \mathrm{PV}>5 \mathrm{PVU}$; $160^{\circ} \mathrm{W}$; Fig. 9). Continuous midtropospheric QG ascent is present ahead of trough T2 (cf. Fig. S14 and section $\mathrm{S} 4$ ).

The downstream ridge (R2) in the eastern North Pacific was strongly influenced by repeated WCB activity at its western flank ahead of trough T2 (cf. section S2). We discuss this activity in more detail with upper-level fields at $T+87 \mathrm{~h}$ when the ridge is amplified and indication of the major WCB is present.

At this time the diabatic outflow of WCB2, centered at $52^{\circ} \mathrm{N}, 160^{\circ} \mathrm{W}$ (Fig. $5 \mathrm{c}$ ), amplifies the western flank of the downstream ridge $\mathrm{R} 2$. At the tip of trough T2 a band of midlevel ascent (red contours south of $40^{\circ} \mathrm{N}, 160^{\circ} \mathrm{W}$ in Fig. $5 \mathrm{c}$ ) indicates the formation of another WCB (WCB3; cf. Figs. S6c and S7c). Because of a very intense upper-level PV gradient over Alaska, a local minimum of negative $\mathrm{PV}$ advection is present $\left(-1.1 \mathrm{PVU} \mathrm{h}^{-1} ; 62^{\circ} \mathrm{N}, 134^{\circ} \mathrm{W}\right.$; Figs. $5 \mathrm{c}$ and 3$)$. Here, the upper-level divergent outflow reflects the remnants of an earlier WCB (WCB1) that initially amplified ridge $\mathrm{R} 2$.

The time series of negative PV advection by the irrotational wind in the eastern North Pacific (Figs. S12 and S13, as well as the animation in the online supplemental material) illustrates that maximum interaction with the extratropical flow in the entire North Pacific region from $T+60$ to $T+108 \mathrm{~h}$ (Fig. 3 ) is due to repeated diabatic WCB outflow injecting low-PV air into ridge R2. Likewise, rapidly ascending air parcels align along the PV gradient in ridge R2 (cf. Figs. S2d and S3d and section $\mathrm{S} 1 \mathrm{~b}$ ). Altogether this corroborates that the diabatically driven outflow of a continuous sequence of WCBs was crucial in the strong amplification of downstream ridge $\mathrm{R} 2$.

A cross section at $T+87 \mathrm{~h}$ indicates the downstream ridge R2 as a "lens" of upper-level low-PV air extending from $50^{\circ}$ to $60^{\circ} \mathrm{N}$ (Fig. 8e). This region of low-PV air is just ahead and above a baroclinic zone, which extends from about $48^{\circ} \mathrm{N}$ at low levels to the tropopause at $60^{\circ} \mathrm{N}$. In contrast to the ascent during the preconditioning and ET stages, ascent in the DS-WCB stage occurs almost entirely slantwise along the tilted moist isentropes, indicating the fundamentally different midlatitude baroclinic evolution along with downstream extratropical cyclogenesis. For the DS-WCB stage the tropopause height is at about $200 \mathrm{hPa}$ and thus much lower compared to the upstream ET stage. The ridging also occurred below the 345-K isentropic level. In the absence of ET the downstream WCB activity is also much weaker, and no ridge 
building is evident (Fig. 8f; cf. Figs. S2d and S3d and section S1b).

\section{Characteristics of diabatic outflow modifying the upper-level midlatitude flow}

In the previous section we showed that the midlatitude flow modification is predominantly governed by the interaction of diabatically driven outflow from different weather systems. Thereby, the nature of the underlying diabatically enhanced ascent is different for the different weather systems (PRE, TC/ET, DS-WCB). Common to all, the diabatic outflow result in a net transport of low-PV air to the upper troposphere, ridge building, a strengthening of the tropopause PV gradient, the evolution of a midlatitude jet streak, and a lifting of the tropopause.

Here, we explore characteristics of these diabatic outflow from a combined Lagrangian and Eulerian perspective. Therefore, bundles of trajectories exhibiting rapid ascent, representing air parcels passing through the PRE, the transitioning TC, and the DSWCB, are discussed (Fig. 10; cf. section 3f).

Early during ET, almost upright ascent occurs in the TC inner core and the TC outflow turns anticyclonically equatorward to the west (pale blue-red-colored trajectories in Fig. 10a). To the northeast of the TC, a second bundle of trajectories reflects the PRE (greenyellow-orange-colored trajectories in Fig. 10a). These air parcels initially move poleward in the lower troposphere $(>700 \mathrm{hPa}$, green). Rapid ascent occurs when the air parcels impinge on the baroclinic zone [transition from air parcels located at $>700 \mathrm{hPa}$ (green) to $<300 \mathrm{hPa}$ (orange); Fig. 10a] and experience largescale forcing for ascent (cf. Fig. 7). Subsequently, the trajectories turn anticyclonically eastward and reach jet level. The diabatically enhanced outflow of the PRE is aligned along the midlatitude waveguide and initial ridge building occurs.

Later during ET, the diabatic outflow of the transitioning TC turns from being directed into the tropics (Fig. 10a) to being directed directly into the initial downstream ridge R1 (Fig. 10b), which was strongly amplified. The ascent in the transitioning TC becomes more tilted [transition from air parcels located at $>900 \mathrm{hPa}$ (dark blue) close to the TC center to $<200 \mathrm{hPa}$ (red) to the north of the TC; Fig. 10b] and is directed poleward. At this stage air parcels emerging from the northeast of the transitioning $\mathrm{TC}$ also experience strong ascent in the baroclinic zone, reflecting ongoing PRE activity and the formation of a WCB (Fig. 10b, pale green-orange colored; cf. Fig. S2c). An animation for the 6-hourly
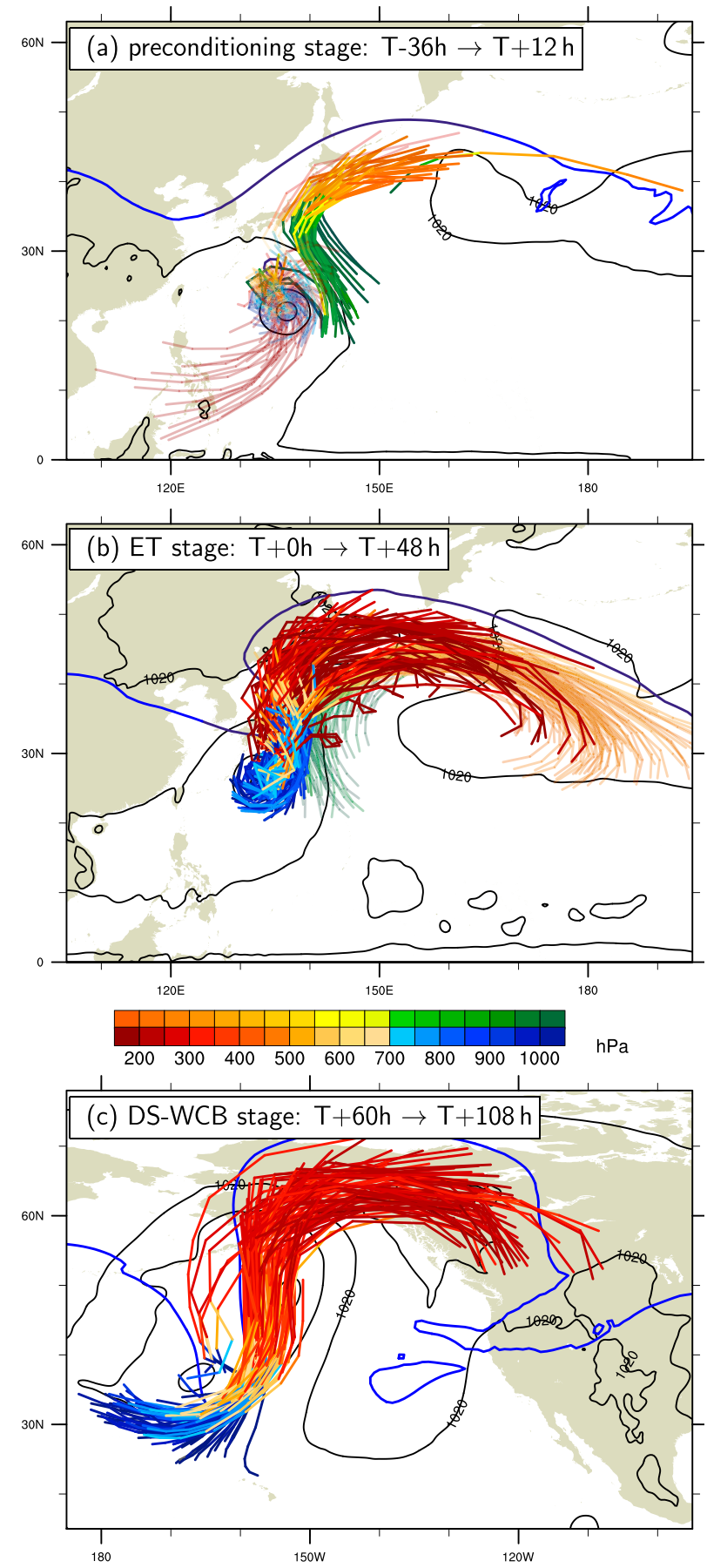

FIG. 10. Forward trajectories computed for $48 \mathrm{~h}$ and fulfilling the criterion to ascend more than $8500 \mathrm{~m}$ in $48 \mathrm{~h}$. See text for details. Start and end times are indicated in each caption. MSLP (black contour every $10 \mathrm{hPa}$ ) at trajectory start time, PV (3-PVU contour in blue) at the isentropic levels of (a),(b) 345 and (c) $335 \mathrm{~K}$ at trajectory end time. Trajectories are colored by their pressure height and every 50th trajectory is shown. In (a),(b) the blue-red color scheme indicates TC trajectories, and the green-orange scheme PRE trajectories. In (c) downstream WCB trajectories are shown. In (a) trajectories not attributed to the PRE and in (b) trajectories not attributed to the transitining TC appear in pale colors. 
TABLE 2. Characteristics of the flow and of the trajectories during the different stages of ET. Data times are with respect to recurvature $(T=0 \mathrm{~h})$. Trajectory times are with respect to trajectory start $(t=0 \mathrm{~h})$. Trajectories are calculated $48 \mathrm{~h}$ forward, ascend more than $8500 \mathrm{~m}$ during this period, and are attributed to the PRE, ET, and DS-WCB stages of ET, as outlined in section 3f. Only mean characteristics for the trajectory bundles are shown and the standard deviation is indicated. The full statistical distribution is shown in Fig. S15 in the online supplemental material.

\begin{tabular}{lccc}
\hline \hline & PRE & ET & DS-WCB \\
\hline Time of max interaction & $T+6 \mathrm{~h}$ & $T+45 \mathrm{~h}$ & $T+87 \mathrm{~h}$ \\
Negative PV advection $\left(\mathrm{PVU} \mathrm{h}^{-1}\right)$ & -1.27 & -2.03 & -1.09 \\
Representative trajectory end time & $T+12 \mathrm{~h}$ & $T+48 \mathrm{~h}$ & $T+108 \mathrm{~h}$ \\
No. of trajectories & 1798 & 4727 & 4788 \\
Lat $(t=48 \mathrm{~h})\left({ }^{\circ} \mathrm{N}\right)$ & $41.5 \pm 4.4$ & $42.9 \pm 5.5$ & $60.7 \pm 5.7$ \\
$p(t=48 \mathrm{~h})(\mathrm{hPa})$ & $234 \pm 36$ & $183 \pm 38$ & $256 \pm 40$ \\
$\Theta(t=48 \mathrm{~h})(\mathrm{K})$ & $345 \pm 5$ & $355 \pm 6$ & $334 \pm 3$ \\
$\Delta \Theta=\Theta(48 \mathrm{~h})-\Theta(0 \mathrm{~h})(\mathrm{K})$ & $40.1 \pm 6.8$ & $49.4 \pm 8.9$ & $35.8 \pm 4.1$ \\
$\mathrm{PV}-\mathrm{PV}$ cli $(48 \mathrm{~h})(\mathrm{PVU})$ & $-1.6 \pm 1.1$ & $-3.3 \pm 1.8$ & $-4.7 \pm 2.1$ \\
\hline
\end{tabular}

trajectory starting times is given in the online supplemental material.

Finally, we focus on the evolution of one of the extratropical WCBs that emerged ahead of downstream trough T2 in the eastern North Pacific (Fig. 10c). WCB inflow is located south of the center of the forming downstream cyclone (Fig. 10c, blue colors). As is typical for WCBs, ascent occurs slantwise over a large region ahead of the trough (transition from dark blue to dark red colors). Subsequently, WCB outflow diverges over a vast region into the strongly amplified downstream ridge (R2, red-colored trajectory segments; cf. Fig. S2d).

The trajectories show that although similar strong ascent occurs in the PRE, ET, and DS-WCB airstreams and their diabatically enhanced outflow all result in the amplification of a ridge, the tracks of air parcels through these weather systems have different pathways. Likewise, characteristics of the different diabatic outflow differ (Table 2 and Fig. S15).

From an Eulerian perspective the minimum in negative PV advection by the irrotational wind shows remarkable differences. It is strongest with $-2.0 \mathrm{PVU} \mathrm{h}^{-1}$ for the ET system, followed by the negative PV advection by the irrotational wind in the PRE outflow $\left(-1.3 \mathrm{PVUh}^{-1}\right)$ and by the downstream WCB $\left(-1.1 \mathrm{PVUh}^{-1}\right)$.

Mean, minimum, and maximum characteristics of the air parcels traveling along the different trajectory bundles are explored at outflow time $(t=48 \mathrm{~h}$; Table 2 and see Fig. S15 for minima and maxima). For the preconditioning stage, air parcels reach the upper troposphere at a pressure height of on average $234 \mathrm{hPa}$ (ranging from 350 to $123 \mathrm{hPa}$ ) and at an average isentropic level of $345 \mathrm{~K}$ (from 328 to $363 \mathrm{~K}$ ). The PRE ascent goes along with strong diabatic heating, reflected in a change of potential temperature from the trajectory starting time $(t=0 \mathrm{~h})$ to the end time $(t=48 \mathrm{~h})$ of more than $40 \mathrm{~K}(29-63 \mathrm{~K})$. The PRE outflow also exhibits a negative $\mathrm{PV}$ anomaly compared to climatological values $(-1.6 \mathrm{PVU})$. The relatively low absolute value of this anomaly is due to the low latitude of the PRE outflow $\left(41.5^{\circ} \mathrm{N}\right)$, where climatologically PV is low (more details discussing Fig. S15 are provided in the online supplemental material). These characteristics underpin that PRE outflow is important in initially lifting the tropopause and building a ridge to the northeast of the transitioning TC.

The very intense TC-extratropical flow interaction during the ET stage is reflected in the characteristics of the ET outflow. On average air parcels reach a height of $183 \mathrm{hPa}(333-106 \mathrm{hPa})$ with an average potential temperature of $355 \mathrm{~K}(337-389 \mathrm{~K})$, which is thus $50 \mathrm{hPa}$ higher and $10 \mathrm{~K}$ warmer than during the preconditioning stage. Consequently, the diabatic heating is also more intense and reaches on average more than $49 \mathrm{~K}$ (29$89 \mathrm{~K})$. As the tropopause reaches much higher and slightly farther poleward $\left(42.9^{\circ} \mathrm{N}\right)$, the climatological PV anomaly is much lower ( $-3.3 \mathrm{PVU})$, reflecting the very intense ridge building during the actual ET.

It is interesting to compare these tropically influenced diabatic outflow to the extratropical diabatic outflow of the downstream WCB. As a result of much less intense diabatic heating $[\Delta \Theta=33 \mathrm{~K}(23-49 \mathrm{~K})]$, the pressure height is lowest on average for the DS-WCB [255 hPa $(419-153 \mathrm{hPa})]$ and so is the average potential temperature $[330 \mathrm{~K}(318-344 \mathrm{~K})]$. However, as the DS-WCB still results in a very pronounced downstream ridge that extends very far poleward $\left(60.7^{\circ} \mathrm{N}\right)$, where climatological PV is high (5 PVU; Fig. S15), and the climatological tropopause is low, the DS-WCB produces the most intense PV anomaly with respect to climatology of, on average, $-4.43 \mathrm{PVU}$, which corroborates its potential for the onset of blocking. 
(a) 1. Preconditioning

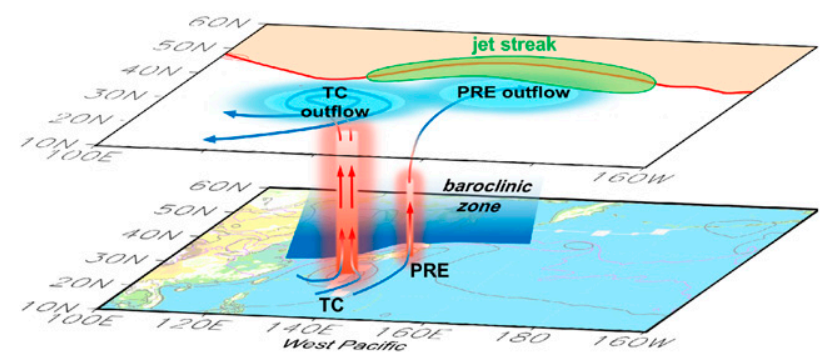

(b) 2. TC - midlatitude flow interaction

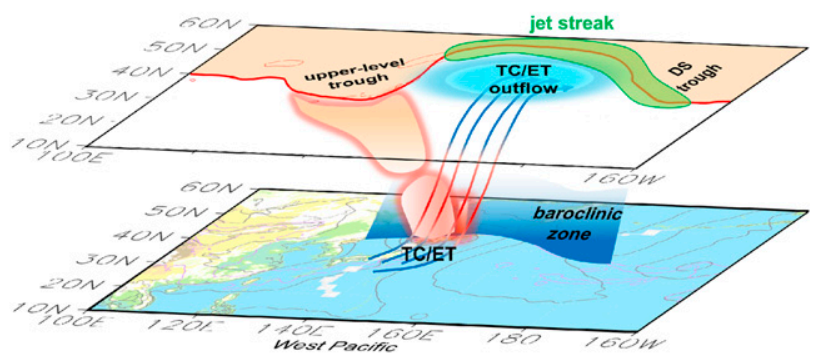

(c) 3. Downstream flow amplification

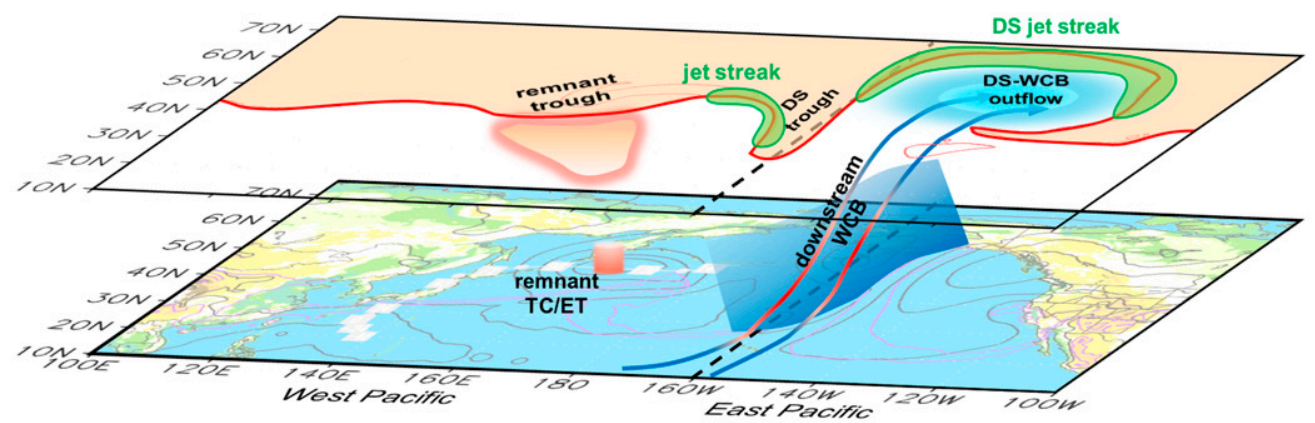

FIG. 11. Schematic of the three stages of ET based on this study. See detailed description in section 7. Red objects indicate positive PV associated with the transitioning TC and PRE. Light blue regions at upper levels indicate low-PV air in the outflow of the weather systems. The jet streaks are indicated in green, the upper-level waveguide (3 PVU) with a red contour, and orange shading is to the north. Dark blue tilted surfaces indicate low- and midlevel baroclinic zones. Trajectories of rapidly ascending air parcels are indicated by blue-red-blue lines, reflecting the diabatic PV modification. (a) Preconditioning stage of ET with contours at lower surfaces showing MSLP (every 8 hPa, black) and equivalent potential temperature (320 and $330 \mathrm{~K}$, violet), as well as contours at the upper surface showing $3 \mathrm{PVU}$ at $200 \mathrm{hPa}$ at $T+12 \mathrm{~h}$. (b) The TC-extratropical flow interaction stage of ET (ET stage) showing the same fields as in (a), but at $T+60 \mathrm{~h}$ and $3 \mathrm{PVU}$ at $335 \mathrm{~K}$. (c) The downstream flow amplification stage of ET (DS-WCB stage) showing the same fields as in (b), but at $T+108 \mathrm{~h}$. Note the eastward extension of the domain compared to (a) and (b).

\section{A conceptual model of ET}

This study investigates the role of diabatic outflow from different weather system categories in upper-level midlatitude flow amplification based on a representative composite scenario of strong interaction ET cases. Here, we summarize our main findings in a conceptual model of western North Pacific ET (Fig. 11).

ET and important upper-level midlatitude flow amplification occurs during three stages, each involving strong diabatic outflow due to latent heat release in rapidly ascending airstreams, associated with different weather system categories (Fig. 11 and section 5; cf. sections S1 and S2): 1) the preconditioning stage, 2) the ET stage, and 3) the downstream WCB stage. The robustness of these stages has been demonstrated for each case and in sensitivity simulations with parameterizations affecting cloud condensational processes altered (section 4).

Preconditioning (preconditioning stage; Fig. 11a) Poleward advection of moist tropical air with the low-level TC circulation may trigger PRE convection and PRE outflow across a baroclinic zone to the northeast of the still purely tropical TC (cf. Galarneau et al. 2010). Ascent in the TC inner core is convective and upright, and its outflow gradually turns from being directed equatorward to being directed poleward at this early stage of ET. The diabatic PRE and later also the TC outflow yield an initial amplification of the trough-ridge couplet and, overall, a favorable environment for extratropical development to the north of the TC, which constitutes an important preconditioning to the actual ET.

TC-extratropical flow interaction (ET stage; Fig. 11b) Ridge building occurs directly downstream of the transforming TC as a result of the joint interaction of the low-level TC circulation with the baroclinic zone and the TC outflow with the upper-level midlatitude jet (Atallah and Bosart 2003; Riemer et al. 2008; Torn 2010; Archambault et al. 2013; Grams et al. 2013b). Thereby, the remnants of the TC inner core become more and more tilted and ascent gradually transitions 
from being convectively upright to being more slantwise along the moist isentropes in the evolving warm sector. Continuous diabatic PV production along the baroclinic zone and the associated cyclonic circulation maintains the poleward advection of tropical air at lower levels and, thus, the diabatic outflow aloft. This yields an acceleration of a midlatitude jet streak, an amplification of the upstream trough and first downstream ridge, and an anchoring of this trough-ridge couplet.

Downstream flow amplification (DS-WCB stage; Fig. 11c) - The PRE- and ET-induced ridge building and jet acceleration triggers downstream development in the subsequent days by enhancing cyclogenesis, WCB activity, and poleward moisture transport in downstream regions. In the ET scenario presented here, a period of prolonged WCB outflow activity ahead of an amplifying downstream trough triggers ridge building and amplification of a pronounced second downstream ridge in the eastern North Pacific and over western North America. One extratropical WCB alone would presumably not yield such an important shift of the regional weather pattern. None of this behavior is present in the absence of ET.

Although different weather systems are involved (PRE, transitioning TC, DS-WCB), for each a similar key sequence of physical processes acts to amplify the midlatitude flow. Latent heat release in rapidly ascending air leads to a net transport of low-PV air into the upper troposphere (cf. Grams et al. 2013b). Negative PV advection by the irrotational wind associated with the diabatically driven divergent outflow of these weather systems initiates ridge building, strengthens the waveguide, accelerates and anchors a midlatitude jet streak, and overall amplifies the midlatitude upper-level Rossby wave pattern (section 5).

This study newly contrasts characteristics of the PRE, TC, and downstream WCB diabatic outflow in terms of the intensity of the diabatic ascent and outflow height (section 6). The ascent in the transitioning TC and along the baroclinic zone during ET results in the strongest negative PV advection by the irrotational wind and exhibits, on average, the strongest diabatic heating $(49 \mathrm{~K})$. Furthermore, the transitioning TC outflow is on average located at the highest isobaric level $(150 \mathrm{hPa})$, followed by the PRE and downstream WCB outflow, respectively. Despite these differences, each of the weather systems interact with the midlatitude upper-level flow in a similar manner.

\section{Discussion and future work}

This study newly shows that during western North Pacific ET cases associated with strong TC-extratropical flow interactions, a similar sequence of physical processes — resulting in diabatic outflow at jet level—-tends to act individually in different weather systems (PRE, transitioning TC, DS-WCB) and jointly yield a highly amplified Rossby wave pattern. Earlier studies of ET highlighted this sequence of physical processes in relation to the transitioning TC only (e.g., Bosart and Lackmann 1995; Atallah and Bosart 2003; Agustí-Panareda et al. 2004; Riemer et al. 2008; Torn 2010; Grams et al. 2013b).

Here, we investigate a control and no-TC simulation for one composite of $12 \mathrm{ET}$ cases over the western North Pacific in September associated with strong TCextratropical flow interactions. Although we demonstrated the robustness of the numerical simulations to model perturbations, other composites would be worth investigating, for instance, for all ETs in different months, an entire TC season, other ocean basins, or only weak ET cases. Our simulations are performed with a regional numerical weather prediction model. However, the downstream impact of ET extends over at least an entire ocean basin, if not an entire hemisphere. Therefore, it is desirable to investigate the downstream impact of ET using a global model such as the National Center for Atmospheric Research Model for Prediction Across Scales (MPAS) or the Deutscher Wetterdienst Icosahedral nonhydrostatic general circulation model (ICON).

We do not claim that dry processes are not important in the formation of the upper-level Rossby wave pattern. Rather, the no-TC/no-LH experiments corroborate earlier studies that dry dynamics are fundamental to the downstream development of Rossby waves during ET (e.g., Harr et al. 2000; Scheck et al. 2011a,b; Keller et al. 2014) and for downstream development more generally (e.g., Chang 2000; Teubler and Riemer 2016). We also show that the QG ascent increases with the amplifying flow pattern. We argue that this initial dry-dynamically forced ascent triggers strong latent heat release in the different weather system categories and thus moist processes result in strongly enhanced ascent and diabatic outflow compared to dry dynamics alone. In that light, Quinting and Jones (2016) demonstrated that the contribution of dry dynamics to the ascent and TC-midlatitude flow interaction only accounts for the smaller fraction of the observed strengths during ET. They concluded that moist processes strongly enhance the ascent and interaction. Our study complements this reasoning by demonstrating that diabatic processes associated with strong latent heat release are crucial in yielding a highly amplified flow pattern. Specifically, we show that in the absence of ET, of strong meridional moisture transport, and of strong latent heat release the midlatitude flow pattern is substantially less amplified.

Our study also documents a potentially important preconditioning for strong ET cases due to PRE activity prior 
to the actual ET process. This preconditioning yields a favorable environment for extratropical development prior to the actual ET. The comparison to the no-TC simulation and a preliminary sensitivity simulation suppressing the PRE suggests that the preconditioning is potentially essential for the reintensification of the TC during the extratropical stage and the downstream flow amplification. Likewise, Quinting and Jones (2016) argued that the lowlevel moisture transport in ET cases with a strong downstream flow response causes an early flow amplification due to enhanced ascent and divergent outflow to the northeast of the TC and a slightly stronger cyclone later. A similar impact of a PRE on the large-scale midlatitude environment such that it alters the subsequent track of a TC undergoing ET has recently been reported by Galarneau (2015) for the ET of Tropical Cyclone Isaac (2012). Also, for Hurricane Sandy (2012) it was hypothesized that an extratropical WCB led to an important preconditioning before Sandy itself further increased the tropopause height to its north and strongly amplified its upstream trough (Grams 2013). For the ET of Typhoon Choi-Wan (2009), Keller and Grams (2014) showed that a diabatic Rossby wave (DRW) led to an important preconditioning. In a modeling study, Choi-Wan is found to be more intense and the downstream flow more amplified for the scenario with the DRW present compared to a scenario with the DRW absent. Earlier studies documented that a recurving TC may directly modify the midlatitude environment, with which it interacts (e.g., McTaggart-Cowan et al. 2001; Klein et al. 2002). Bosart and Lackmann (1995) documented that this modification may result in a positive feedback between the TC outflow and the diabatic ridging, enhancing the subsequent extratropical reintensification in some cases. Such a positive feedback has also been seen here by the joint interaction of the PRE and TC circulation with the midlatitude flow. However, the importance of the preconditioning by weather systems other than the TC itself to the downstream impact remains unclear and is subject of ongoing work.

The study also shows the important role of moisture transport on the eastern flank of the recurving TC (and in the monsoon trough in the no-TC simulation) and ahead of the downstream trough. Similar to the detailed study by Cordeira et al. (2013), this moisture transport has characteristics of atmospheric rivers (ARs; Newell et al. 1992) or tropical moisture exports (TMEs; Knippertz et al. 2013). It would be worth investigating more quantitatively if ARs/TMEs solely are important in Rossby wave amplification or only in concert with diabatic weather systems (such as a PRE, TC, or WCB), as indicated in this study. Moreover, this study suggests that ET tends to alter moisture transport from the tropics to a more poleward direction in conjunction with more amplified flow. This modification in turn indirectly modulates the upper-level midlatitude flow by altering regions and the intensity of latent heat release and associated upper-level diabatic outflow (cf. Keller and Grams 2014).

Beyond the specific role of moisture transport, another interesting question is whether strong larger-scale diabatic outflow from other types of weather systems has a similar impact on the large-scale flow. In addition to PREs, TC/ETs, and WCBs, mesoscale convective systems (MCSs) and DRWs exhibit strong diabatic outflow. Rodwell et al. (2013) showed that the misrepresentation of enhanced MCS activity over North America leads to severe forecast busts over Europe, as a result of an inaccurate representation of the Rossby wave pattern over North America and Europe, which is modulated by MCS diabatic outflow.

In recent years some studies also tried to link the Rossby wave amplification during ET to HIW in downstream regions (e.g., Cordeira and Bosart 2010; Grams et al. 2011; Keller et al. 2014; Harr and Archambault 2016; Grams and Blumer 2015; Pantillon et al. 2015). Here, we did not investigate the role of the amplified Rossby wave packet in downstream HIW, although, based on other studies, HIW such as anomalous heat or cold and/or heavy precipitation over North America can be expected to accompany a highly amplified flow pattern (cf. Keller et al. 2014; Keller and Grams 2014; Harr and Archambault 2016). A more systematic investigation of the link of downstream HIW to an ET event upstream is needed.

In the present study a period of prolonged WCB outflow activity is important in generating a highly amplified ridge over the eastern North Pacific, resembling a blocking-type pattern. Recently, Pfahl et al. (2015) showed that diabatic PV reduction is a first-order process in the onset of blocking. The potential onset of a blocking may also mark a large-scale weather regime transition that affects continent-scale regions. In that regard Archambault et al. (2010) showed that a single major cool season precipitation event over the western North Atlantic can induce the transition of the largescale flow pattern over the North Atlantic from zonal to highly amplified/blocked. Ongoing work by the authors investigates to what extent ET and the temporal clustering of diabatically influenced weather systems support the diabatic generation of blocking ridges and may be responsible for weather regime transitions.

Acknowledgments. The contribution of CMG was supported by the German Research Foundation (DFG) as part of the research unit PANDOWAE (FOR896) and finished while CMG held a Swiss National Science Foundation (SNSF) Ambizione fellowship (PZ00P2_148177/1). 
The majority of this work was performed while HMA was an NRC postdoctoral fellow at the Naval Postgraduate School in Monterey, California. The Office of Naval Research Marine Meteorology Program (Grant ONRN0001413WX20832) and the National Science Foundation (Grant AGS-0849356) supported the contribution of HMA. We are deeply grateful to Heini Wernli for generous support that facilitated the collaboration. We acknowledge the Federal Office of Meteorology and Climatology MeteoSwiss, the Deutscher Wetterdienst (DWD), and the Center for Climate Systems Modeling (C2SM) at ETH Zurich for support with the COSMO model and for providing access to ECMWF data. We thank Sarah Jones, Pat Harr, Rich Moore, and Heini Wernli for several discussions that helped interpreting the results and outlining the manuscript. Likewise we thank Julia Keller, Julian Quinting, Michael Riemer, the Atmospheric Dynamics group at ETH, and the PANDOWAE Young Scientists for sharing their ideas and discussing our project. We are grateful to Sylvaine Ferrachat, Anne Roches, and Stephan Pfahl for support running the COSMO model and providing the code for the no-LH experiment. Thanks are due to Bob Creasey at NPS for his generous assistance to HMA in data processing. The data analysis and visualization was partly done using the NCAR Command Language (UCAR/NCAR/ CISL/VETS 2014). The code used to determine the QG forcing was derived from code in NDDIAG, a diagnostics package developed and supported by the U.K.'s National Centre for Atmospheric Science Computational Modeling Services (NCAS-CMS). We thank Maxi Boettcher, Heini Wernli, and Sue Gray for their support and giving access to this diagnostic. Finally, we thank the editor Ron McTaggartCowan and two anonymous reviewers for constructive criticism and thoughtful feedback that substantially helped to improve the presentation of our results.

\section{REFERENCES}

Agustí-Panareda, A., C. Thorncroft, G. Craig, and S. Gray, 2004: The extratropical transition of Hurricane Irene (1999): A potential-vorticity perspective. Quart. J. Roy. Meteor. Soc., 130, 1047-1074, doi:10.1256/qj.02.140.

Ahmadi-Givi, F., G. C. Graig, and R. S. Plant, 2004: The dynamics of a midlatitude cyclone with very strong latent-heat release. Quart. J. Roy. Meteor. Soc., 130, 295-323, doi:10.1256/qj.02.226.

Aiyyer, A., 2015: Recurving western North Pacific tropical cyclones and midlatitude predictability. Geophys. Res. Lett., $\mathbf{4 2}$, 7799-7807, doi:10.1002/2015GL065082.

Anwender, D., P. A. Harr, and S. C. Jones, 2008: Predictability associated with the downstream impacts of the extratropical transition of tropical cyclones: Case studies. Mon. Wea. Rev., 136, 3226-3247, doi:10.1175/2008MWR2249.1.

Archambault, H. M., D. Keyser, and L. F. Bosart, 2010: Relationships between large-scale regime transitions and major cool-season precipitation events in the northeastern United States. Mon. Wea. Rev., 138, 3454-3473, doi:10.1175/2010MWR3362.1.
— L. F. Bosart, D. Keyser, and J. M. Cordeira, 2013: A climatological analysis of the extratropical flow response to recurving western North Pacific tropical cyclones. Mon. Wea. Rev., 141, 2325-2346, doi:10.1175/MWR-D-12-00257.1.

, D. Keyser, L. F. Bosart, C. A. Davis, and J. M. Cordeira, 2015: A composite perspective of the extratropical flow response to recurving western North Pacific tropical cyclones. Mon. Wea. Rev., 143, 1122-1141, doi:10.1175/MWR-D-14-00270.1.

Atallah, E. H., and L. F. Bosart, 2003: The extratropical transition and precipitation distribution of Hurricane Floyd (1999). Mon. Wea. Rev., 131, 1063-1081, doi:10.1175/ 1520-0493(2003)131<1063:TETAPD > 2.0.CO;2.

Baek, E.-H., J.-H. Kim, J.-S. Kug, and G.-H. Lim, 2013: Favorable versus unfavorable synoptic backgrounds for indirect precipitation events ahead of tropical cyclones approaching the Korean Peninsula: A comparison of two cases. Asia-Pac. J. Atmos. Sci., 49, 333-346, doi:10.1007/s13143-013-0032-z.

Boettcher, M., and H. Wernli, 2011: Life cycle study of a diabatic Rossby wave as a precursor to rapid cyclogenesis in the North Atlantic-Dynamics and forecast performance. Mon. Wea. Rev., 139, 1861-1878, doi:10.1175/2011MWR3504.1.

Bosart, L. F., and G. M. Lackmann, 1995: Postlandfall tropical cyclone reintensification in a weakly baroclinic environment: A case study of Hurricane David (September 1979). Mon. Wea. Rev., 123, 3268-3291, doi:10.1175/1520-0493(1995)123<3268: PTCRIA $>2.0 . \mathrm{CO} ; 2$.

—, J. M. Cordeira, T. J. Galarneau, B. J. Moore, and H. M. Archambault, 2012: An analysis of multiple predecessor rain events ahead of Tropical Cyclones Ike and Lowell: 10-15 September 2008. Mon. Wea. Rev., 140, 1081-1107, doi:10.1175/ MWR-D-11-00163.1.

Browning, K. A., P. Panagi, and G. Vaughan, 1998: Analysis of an ex-tropical cyclone after its reintensification as a warm-core extratropical cyclone. Quart. J. Roy. Meteor. Soc., 124, 23292356, doi:10.1002/qj.49712455108.

Byun, K.-Y., and T.-Y. Lee, 2012: Remote effects of tropical cyclones on heavy rainfall over the Korean PeninsulaStatistical and composite analysis. Tellus, 64A, 14983, doi:10.3402/ tellusa.v64i0.14983.

Carlson, T. N., 1980: Airflow through midlatitude cyclones and the comma cloud pattern. Mon. Wea. Rev., 108, 1498-1509, doi:10.1175/1520-0493(1980)108<1498:ATMCAT>2.0.CO;2.

Chang, E. K. M., 2000: Wave packets and life cycles of troughs in the upper troposphere: Examples from the Southern Hemisphere summer season of 1984/85. Mon. Wea. Rev., 128, 25-50, doi:10.1175/1520-0493(2000)128<0025:WPALCO > 2.0.CO;2.

Charney, J., 1955: The use of the primitive equations of motion in numerical prediction. Tellus, 7, 22-26, doi:10.1111/ j.2153-3490.1955.tb01138.x.

Clough, S. A., C. S. A. Davitt, and A. J. Thorpe, 1996: Attribution concepts applied to the omega equation. Quart. J. Roy. Meteor. Soc., 122, 1943-1962, doi:10.1002/qj.49712253610.

Cordeira, J. M., and L. F. Bosart, 2010: The antecedent large-scale conditions of the "perfect storms" of late October and early November 1991. Mon. Wea. Rev., 138, 2546-2569, doi:10.1175/ 2010MWR3280.1.

_ F. M. Ralph, and B. J. Moore, 2013: The development and evolution of two atmospheric rivers in proximity to western North Pacific tropical cyclones in October 2010. Mon. Wea. Rev., 141, 4234-4255, doi:10.1175/MWR-D-13-00019.1.

Dacre, H. F., and S. L. Gray, 2009: The spatial distribution and evolution characteristics of North Atlantic cyclones. Mon. Wea. Rev., 137, 99-115, doi:10.1175/2008MWR2491.1. 
Davies, H. C., and M. Didone, 2013: Diagnosis and dynamics of forecast error growth. Mon. Wea. Rev., 141, 2483-2501, doi:10.1175/MWR-D-12-00242.1.

Davis, C. A., and K. A. Emanuel, 1991: Potential vorticity diagnostics of cyclogenesis. Mon. Wea. Rev., 119, 1929-1953, doi:10.1175/1520-0493(1991)119<1929:PVDOC > 2.0.CO;2.

Dee, D. P., and Coauthors, 2011: The ERA-Interim reanalysis: Configuration and performance of the data assimilation system. Quart. J. Roy. Meteor. Soc., 137, 553-597, doi:10.1002/qj.828.

Deveson, A. C. L., K. A. Browning, and T. D. Hewson, 2002: A classification of FASTEX cyclones using a height-attributable quasi-geostrophic vertical-motion diagnostic. Quart. J. Roy. Meteor. Soc., 128, 93-117, doi:10.1256/00359000260498806.

DiMego, G. J., and L. F. Bosart, 1982: The transformation of Tropical Storm Agnes into an extratropical cyclone. Part I: The observed fields and vertical motion computations. Mon. Wea. Rev., 110, 385-411, doi:10.1175/1520-0493(1982)110<0385: TTOTSA $>2.0 . \mathrm{CO} ; 2$.

Foley, G. R., and B. N. Hanstrum, 1994: The capture of tropical cyclones by cold fronts off the west coast of Australia. Wea. Forecasting, 9, 577-592, doi:10.1175/1520-0434(1994)009<0577: TCOTCB $>2.0 . \mathrm{CO} ; 2$.

Galarneau, T. J., 2015: Influence of a predecessor rain event on the track of Tropical Cyclone Isaac (2012). Mon. Wea. Rev., 143, 3354-3376, doi:10.1175/MWR-D-15-0053.1.

- L L. F. Bosart, and R. S. Schumacher, 2010: Predecessor rain events ahead of tropical cyclones. Mon. Wea. Rev., 138, 3272 3297, doi:10.1175/2010MWR3243.1.

Grams, C. M., 2011: Quantification of the downstream impact of extratropical transition for Typhoon Jangmi and other case studies. Ph.D. thesis, Karlsruhe Institute of Technology, Karlsruhe, Germany, 334 pp., doi:10.5445/KSP/1000024940.

- 2013: Quantification of Hurricane Sandy's impact on the midlatitude flow. 16th Cyclone Workshop, St-Adèle, QC, Canada, Cyclone Workshop Organizing Committee. [Available online at http://www.atmos.albany.edu/facstaff/kristen/CW16/ CW16_Talks.html.]

, and S. R. Blumer, 2015: European high-impact weather caused by the downstream response to the extratropical transition of North Atlantic Hurricane Katia (2011). Geophys. Res. Lett., 42, 8738-8748, doi:10.1002/2015GL066253.

— , and Coauthors, 2011: The key role of diabatic processes in modifying the upper-tropospheric wave guide: A North Atlantic case-study. Quart. J. Roy. Meteor. Soc., 137, 2174-2193, doi:10.1002/qj.891.

— S. C. Jones, and C. A. Davis, 2013a: The impact of Typhoon Jangmi (2008) on the midlatitude flow. Part II: Downstream evolution. Quart. J. Roy. Meteor. Soc., 139, 2165-2180, doi:10.1002/qj.2119.

$,-\longrightarrow, \ldots$, P. A. Harr, and M. Weissmann, 2013b: The impact of Typhoon Jangmi (2008) on the midlatitude flow. Part I: Upper-level ridgebuilding and modification of the jet. Quart. J. Roy. Meteor. Soc., 139, 2148-2164, doi:10.1002/qj.2091.

- S. T. K. Lang, and J. H. Keller, 2015: A quantitative assessment of the sensitivity of the downstream midlatitude flow response to extratropical transition of tropical cyclones. Geophys. Res. Lett., 42, 9521-9529, doi:10.1002/2015GL065764.

Gray, S. L., C. M. Dunning, J. Methven, G. Masato, and J. M. Chagnon, 2014: Systematic model forecast error in Rossby wave structure. Geophys. Res. Lett., 41, 2979-2987, doi:10.1002/2014GL059282.

Grazzini, F., and F. Vitart, 2015: Atmospheric predictability and Rossby wave packets: Predictability and Rossby wave packets. Quart. J. Roy. Meteor. Soc., 141, 2793-2802, doi:10.1002/qj.2564.
Harr, P. A., and R. L. Elsberry, 2000: Extratropical transition of tropical cyclones over the western North Pacific. Part I: Evolution of structural characteristics during the transition process. Mon. Wea. Rev., 128, 2613-2633, doi:10.1175/1520-0493(2000)128<2613: ETOTCO $>2.0 . \mathrm{CO} ; 2$.

— , and H. M. Archambault, 2016: Dynamics, predictability, and high-impact weather associated with the extratropical transition of tropical cyclones. Dynamics and Predictability of Large-Scale, High-Impact Weather and Climate Events, J. Li et al., Eds., Special Publications of the International Union of Geodesy and Geophysics, Cambridge University Press, 153-167.

_ R. R. Elsberry, and T. F. Hogan, 2000: Extratropical transition of tropical cyclones over the western North Pacific. Part II: The impact of midlatitude circulation characteristics. Mon. Wea. Rev., 128, 2634-2653, doi:10.1175/1520-0493(2000)128<2634: ETOTCO $>2.0 . \mathrm{CO} ; 2$.

$\longrightarrow$, D. Anwender, and S. C. Jones, 2008: Predictability associated with the downstream impacts of the extratropical transition of tropical cyclones: Methodology and a case study of Typhoon Nabi (2005). Mon. Wea. Rev., 136, 3205-3225, doi:10.1175/ 2008MWR2248.1.

Hoskins, B. J., I. Draghici, and H. C. Davies, 1978: A new look at the $\omega$-equation. Quart. J. Roy. Meteor. Soc., 104, 31-38, doi:10.1256/smsqj.43902.

Jones, S. C., and Coauthors, 2003: The extratropical transition of tropical cyclones: Forecast challenges, current understanding, and future directions. Wea. Forecasting, 18, 1052-1092, doi:10.1175/1520-0434(2003)018<1052:TETOTC $>2.0 . C O ; 2$.

Kain, J. S., and J. M. Fritsch, 1993: Convective parameterization for mesoscale models: The Kain-Fritsch scheme. The Representation of Cumulus Convection in Numerical Models, Meteor. Monogr., No. 46, Amer. Meteor. Soc., 165-170, doi:10.1007/ 978-1-935704-13-3_16.

Keller, J. H., and C. M. Grams, 2014: Investigating the impact of Typhoon Choi-Wan (2009) on the mid-latitude flow using eddy kinetic energy analysis. Proc. 31st Conf. on Hurricanes and Tropical Meteorology, San Diego, CA, Amer. Meteor. Soc., 170. [Available online at https://ams.confex.com/ams/ 31Hurr/webprogram/Paper245321.html.]

— S. C. Jones, J. L. Evans, and P. A. Harr, 2011: Characteristics of the TIGGE multimodel ensemble prediction system in representing forecast variability associated with extratropical transition. Geophys. Res. Lett., 38, L12802, doi:10.1029/ 2011 GL047275.

,-- , and P. A. Harr, 2014: An eddy kinetic energy view of physical and dynamical processes in distinct forecast scenarios for the extratropical transition of two tropical cyclones. Mon. Wea. Rev., 142, 2751-2771, doi:10.1175/MWR-D-13-00219.1.

Kessler, E., 1969: On the Distribution and Continuity of Water Substance in Atmospheric Circulations. Meteor. Monogr., No. 32, Amer. Meteor. Soc., 84 pp.

Klein, P. M., P. A. Harr, and R. L. Elsberry, 2000: Extratropical transition of western North Pacific tropical cyclones: An overview and conceptual model of the transformation stage. Wea. Forecasting, 15, 373-395, doi:10.1175/1520-0434(2000)015<0373: ETOWNP $>2.0 . \mathrm{CO} ; 2$.

,-- , and — 2002: Extratropical transition of western North Pacific tropical cyclones: Midlatitude and tropical cyclone contributions to reintensification. Mon. Wea. Rev., 130, 2240-2259, doi:10.1175/1520-0493(2002)130<2240:ETOWNP>2.0.CO;2.

Knippertz, P., H. Wernli, and G. Gläser, 2013: A global climatology of tropical moisture exports. J. Climate, 26, 3031-3045, doi:10.1175/JCLI-D-12-00401.1. 
Lang, A. A., and J. E. Martin, 2013: The structure and evolution of lower stratospheric frontal zones. Part II: The influence of tropospheric ascent on lower stratospheric frontal development. Quart. J. Roy. Meteor. Soc., 139, 1798-1809, doi:10.1002/qj.2074.

Madonna, E., S. Limbach, C. Aebi, H. Joos, H. Wernli, and O. Martius, 2014a: On the co-occurrence of warm conveyor belt outflows and PV streamers. J. Atmos. Sci., 71, 3668-3673, doi:10.1175/JAS-D-14-0119.1.

_, H. Wernli, H. Joos, and O. Martius, 2014b: Warm conveyor belts in the ERA-Interim dataset (1979-2010). Part I: Climatology and potential vorticity evolution. J. Climate, 27, 3-26, doi:10.1175/JCLI-D-12-00720.1.

Martius, O., C. Schwierz, and H. C. Davies, 2010: Tropopause-level waveguides. J. Atmos. Sci., 67, 866-879, doi:10.1175/2009JAS2995.1.

McTaggart-Cowan, R., J. R. Gyakum, and M. K. Yau, 2001: Sensitivity testing of extratropical transitions using potential vorticity inversions to modify initial conditions: Hurricane Earl case study. Mon. Wea. Rev., 129, 1617-1636, doi:10.1175/ 1520-0493(2001)129<1617:STOETU >2.0.CO;2.

Moore, B. J., L. F. Bosart, D. Keyser, and M. L. Jurewicz, 2013: Synoptic-scale environments of predecessor rain events occurring east of the Rocky Mountains in association with Atlantic basin tropical cyclones. Mon. Wea. Rev., 141, 1022-1047, doi:10.1175/MWR-D-12-00178.1.

Newell, R. E., N. E. Newell, Y. Zhu, and C. Scott, 1992: Tropospheric rivers? - A pilot study. Geophys. Res. Lett., 19, 24012404, doi:10.1029/92GL02916.

Pantillon, F., J.-P. Chaboureau, and E. Richard, 2015: Remote impact of North Atlantic hurricanes on the Mediterranean during episodes of intense rainfall in autumn 2012. Quart. J. Roy. Meteor. Soc., 141, 967-978, doi:10.1002/qj.2419.

Pfahl, S., C. Schwierz, M. Croci-Maspoli, C. M. Grams, and H. Wernli, 2015: Importance of latent heat release in ascending air streams for atmospheric blocking. Nat. Geosci., 8, 610-614, doi:10.1038/ngeo2487.

Quinting, J. F., and S. C. Jones, 2016: On the impact of tropical cyclones on Rossby wave packets: A climatological perspective. Mon. Wea. Rev., 144, 2021-2048, doi:10.1175/MWR-D-14-00298.1.

Riemer, M., and S. C. Jones, 2010: The downstream impact of tropical cyclones on a developing baroclinic wave in idealized scenarios of extratropical transition. Quart. J. Roy. Meteor Soc., 136, 617-637, doi:10.1002/qj.605.

, and - 2014: Interaction of a tropical cyclone with a highamplitude, midlatitude wave pattern: Waviness analysis, trough deformation and track bifurcation. Quart. J. Roy. Meteor. Soc., 140, 1362-1376, doi:10.1002/qj.2221.

— - _ and C. A. Davis, 2008: The impact of extratropical transition on the downstream flow: An idealized modelling study with a straight jet. Quart. J. Roy. Meteor. Soc., 134, 6991, doi:10.1002/qj.189.

Ritchie, E. A., and R. L. Elsberry, 2007: Simulations of the extratropical transition of tropical cyclones: Phasing between the upper-level trough and tropical cyclones. Mon. Wea. Rev., 135, 862-876, doi:10.1175/MWR3303.1.

Rodwell, M. J., and Coauthors, 2013: Characteristics of occasional poor medium-range weather forecasts for Europe. Bull. Amer. Meteor. Soc., 94, 1393-1405, doi:10.1175/BAMS-D-12-00099.1.

Saha, S., and Coauthors, 2010: The NCEP Climate Forecast System Reanalysis. Bull. Amer. Meteor. Soc., 91, 1015-1057, doi:10.1175/2010BAMS3001.1.

Scheck, L., S. C. Jones, and M. Juckes, 2011a: The resonant interaction of a tropical cyclone and a tropopause front in a barotropic model. Part I: Zonally oriented front. J. Atmos. Sci., 68, 405-419, doi:10.1175/2010JAS3482.1.

,,-- and $-2011 \mathrm{~b}$ : The resonant interaction of a tropical cyclone and a tropopause front in a barotropic model. Part II: Frontal waves. J. Atmos. Sci., 68, 420-429, doi:10.1175/ 2010JAS3483.1.

Schumacher, R. S., and T. J. Galarneau, 2012: Moisture transport into midlatitudes ahead of recurving tropical cyclones and its relevance in two predecessor rain events. Mon. Wea. Rev., 140, 1810-1827, doi:10.1175/MWR-D-11-00307.1.

Sekioka, M., 1959: A hypothesis on complex of tropical and extratropical cyclones for typhoon in middle latitudes: IV. Analyses on typhoons invading into the Japan Sea during the period from 1947 to 1956. J. Meteor. Soc. Japan, 37, 111-114.

Sprenger, M., and H. Wernli, 2015: The Lagrangian analysis tool LAGRANTO-Version 2.0. Geosci. Model Dev., 8, 25692586, doi:10.5194/gmd-8-2569-2015.

Steppeler, J., G. Doms, U. Schättler, H. W. Bitzer, A. Gassmann, U. Damrath, and G. Gregoric, 2003: Meso-gamma scale forecasts using the nonhydrostatic model LM. Meteor. Atmos. Phys., 82, 75-96, doi:10.1007/s00703-001-0592-9.

Teubler, F., and M. Riemer, 2016: Dynamics of Rossby wave packets in a quantitative potential vorticity-potential temperature framework. J. Atmos. Sci., 73, 1063-1081, doi:10.1175/ JAS-D-15-0162.1.

Thorncroft, C., and S. C. Jones, 2000: The extratropical transitions of Hurricanes Felix and Iris in 1995. Mon. Wea. Rev., 128, 947-972, doi:10.1175/1520-0493(2000)128<0947:TETOHF>2.0.CO;2.

Tiedtke, M., 1989: A comprehensive mass flux scheme for cumulus parameterization in large-scale models. Mon. Wea. Rev., 117, 1779 1800, doi:10.1175/1520-0493(1989)117<1779:ACMFSF>2.0.CO;2.

Torn, R. D., 2010: Diagnosis of the downstream ridging associated with extratropical transition using short-term ensemble forecasts. J. Atmos. Sci., 67, 817-833, doi:10.1175/2009JAS3093.1.

, and G. J. Hakim, 2015: Comparison of wave packets associated with extratropical transition and winter cyclones. Mon. Wea. Rev., 143, 1782-1803, doi:10.1175/MWR-D-14-00006.1.

UCAR/NCAR/CISL/VETS, 2014: The NCAR Command Language (version 6.1.2). UCAR/NACAR/Computational Information Systems Laboratory/Visualization and Enabling Technologies Section, doi:10.5065/D6WD3XH5.

Uccellini, L. W., and D. R. Johnson, 1979: The coupling of upper and lower tropospheric jet streaks and implications for the development of severe convective storms. Mon. Wea. Rev., 107, 682-703, doi:10.1175/1520-0493(1979)107<0682: TCOUAL $>2.0 . \mathrm{CO} ; 2$.

Wang, Y., Y. Wang, and H. Fudeyasu, 2009: The role of Typhoon Songda (2004) in producing distantly located heavy rainfall in Japan. Mon. Wea. Rev., 137, 3699-3716, doi:10.1175/ 2009MWR2933.1.

Wernli, H., 1997: A Lagrangian-based analysis of extratropical cyclones. II: A detailed case-study. Quart. J. Roy. Meteor. Soc. 123, 1677-1706, doi:10.1002/qj.49712354211.

_ , and H. C. Davies, 1997: A Lagrangian-based analysis of extratropical cyclones. I: The method and some applications. Quart. J. Roy. Meteor. Soc., 123, 467-489, doi:10.1002/ qj. 49712353811

Wu, C.-C., and Y. Kurihara, 1996: A numerical study of the feedback mechanisms of hurricane-environment interaction on hurricane movement from the potential vorticity perspective. J. Atmos. Sci., 53, 2264-2282, doi:10.1175/ 1520-0469(1996)053<2264:ANSOTF > 2.0.CO;2. 